\title{
CrystEngComm
}

Check for updates

Cite this: CrystEngComm, 2017, 19, 6630

Received 3rd July 2017,

Accepted 4th October 2017

DOI: $10.1039 / c 7 c e 01229 b$

rsc.li/crystengcomm

\section{Syntheses, structural diversity, magnetic properties and dye absorption of various Co(II) MOFs based on a semi-flexible 4-(3,5- dicarboxylatobenzyloxy)benzoic acid $\dagger$}

\author{
Xiang-min Meng, ${ }^{\text {ac }}$ Lian-sheng Cui, ${ }^{d}$ Xin-ping Wang, ${ }^{a}$ Xiao-yin Zhang, ${ }^{c}$ \\ Xia Zhang ${ }^{\mathrm{C}}$ and Shuang-yu $\mathrm{Bi}$ (iD*b
}

Five novel Co(II) metal-organic frameworks (MOFs) constructed from semi-flexible 4-(3,5dicarboxylatobenzyloxy)benzoic acid $\left(\mathrm{H}_{3} \mathrm{~L}\right)$, namely $\left\{\left[\mathrm{CO}_{1.5}(\mathrm{HL})\left(4,4^{\prime}-\text { bidpe }\right)_{2}\left(\mathrm{H}_{2} \mathrm{O}\right)\right] \cdot 3 \mathrm{H}_{2} \mathrm{O}\right\}_{n}(1),\left\{\left[\mathrm{CO}_{3}(\mathrm{~L})_{2}\left(4,4^{\prime}-\right.\right.\right.$ bibp) $\left.\left.)_{3}\left(\mu_{2}-\mathrm{O}\right)_{2}\right] \cdot 2 \mathrm{H}_{2} \mathrm{O}\right\}_{n}$ (2), $\left\{[\mathrm{Co}(\mathrm{HL})(1,3-\text { bitl) }) \cdot(1,4-\mathrm{Diox})\}_{n}\right.$ (3), $\left[\mathrm{CO}_{2}(\mathrm{HL})_{2}(3,5-\mathrm{bipd})_{2}\right]_{n}$ (4), and $\{[\mathrm{Co}(\mathrm{HL})(\mathrm{tib})]$ $\left.\cdot 0.5 \mathrm{H}_{2} \mathrm{O} \cdot \mathrm{NMP}\right\}_{n}$ (5) $\left(4,4^{\prime}\right.$-bidpe $=4,4^{\prime}$-bis(imidazolyl)diphenyl ether, 4,4'-bibp = 4,4'-bis(imidazol-1yl)biphenyl, 1,3-bitl = 1,3-bis(1-imidazoly)toluene, 3,5-bipd = 3,5-bis(1-imidazoly)pyridine, and tib = 1,3,5tris(1-imidazolyl)benzene), were synthesized under solvothermal conditions and further characterized by elemental analysis, IR spectra, powder X-ray diffraction (PXRD), thermogravimetric (TG) analysis and singlecrystal X-ray diffraction. Different architectural topologies have been generated by adjusting the $\mathrm{N}$-donor ligands. Single-crystal $X$-ray diffraction analysis reveals that complex 1 shows a rare $1 D \rightarrow 2 D$ polyrotaxane network. Complex 2 possesses an unprecedented 2-nodal $(3,10)$-connected 3D framework with a Schläfli symbol of $\left(4^{3}\right)^{2}\left(4^{6} \cdot 6^{32} \cdot 8^{3}\right)\left(4^{3}\right)^{2}$. When the 2-connected points $\left(\mathrm{H}_{3} \mathrm{~L}\right.$ and 1,3 -bitl ligands) are not calculated, complex 3 shows a hcb uninodal 3-connected 2D network with the Schläfli symbol $\left(6^{3}\right)$, which further constructs a 3D supramolecular structure through $\mathrm{O}-\mathrm{H} \cdots \mathrm{O}$ hydrogen bonds; while the 2 -connected points are taken into account, complex 3 exhibits an unprecedented 3 -nodal $(2,2,4)$-connected network. Complex 4 presents an unprecedented 2-nodal $(3,5)$-connected 3D framework with a $\left(4 \cdot 6^{2}\right)\left(4 \cdot 6^{6} \cdot 8^{3}\right)$ topology, while complex 5 exhibits another unprecedented 2-nodal $(3,5)$-connected 2D framework with a $\left(4^{2} \cdot 6^{7}\right.$ .8)( $\left.4^{2} .6\right)$ Schläfli symbol and shows $2 \mathrm{D} \rightarrow 3 \mathrm{D}$ supramolecular structure through $\mathrm{O}-\mathrm{H} \cdots \mathrm{O}$ hydrogen bonds. Meanwhile, the magnetic properties of complexes 2 and 4 are discussed. Moreover, the dye adsorption and mechanism studies indicate that the pore size, the uncoordinated $O$ atoms in carboxyl groups and the uncoordinated carboxyl groups of the MOFs have significant effects on the dye adsorption capacity.

\section{Introduction}

In recent years, the construction and research of metal-organic frameworks (MOFs) have attracted significant research attention in materials science due to their diverse topological

${ }^{a}$ College of Marine Science and Biological Engineering, Qingdao University of Science and Technology, Qingdao, Shandong 266042, P.R. China

${ }^{b}$ Max Planck Institute for Terrestrial Microbiology \& LOEWE Center for Synthetic Microbiology (SYNMIKRO), Marburg, Germany.

E-mail: shuangyu.bi@synmikro.mpi-marburg.mpg.de

${ }^{c}$ Key Laboratory of Marine Chemistry Theory and Technology, Ministry of Education, College of Chemistry and Chemical Engineering, Ocean University of China, Qingdao, Shandong 266100, P.R. China

${ }^{d}$ College of Chemistry and Environmental Engineering, Baise University, Baise, Guangxi 533000, P.R. China

$\dagger$ Electronic supplementary information (ESI) available. CCDC 1559878-1559880, 1519483 and 1519484. For ESI and crystallographic data in CIF or other electronic format see DOI: 10.1039/c7ce01229b structures $^{1-3}$ and their promising applications in luminescence, $^{4-6}$ magnetism, ${ }^{7,8}$ gas storage, ${ }^{9,10}$ ion exchange, ${ }^{11}$ molecular sensing and separation, ${ }^{12}$ catalysis, ${ }^{13,14}$ dye adsorption ${ }^{15,16}$ and so on. ${ }^{17}$ Particularly, the removal of organic dyes (e.g. methylene blue, rhodamine $\mathrm{B}$, acriflavine hydrochloride, Congo red, brilliant green and methyl orange) from wastewater is becoming a significant application for MOFs depending on the pore shape, and this aspect attracts considerable attention of the majority of chemists. ${ }^{18}$ Dyes are very difficult to degrade because they are highly stable to light and oxidation. ${ }^{19}$ For example, Li's group has reported that Co-based MOFs assembled using 5-(pyridine-4-yl)isophthalic ligands show a good dye adsorption capacity based on appropriate pores. ${ }^{19 a}$ Tamara L. Church's group synthesized an amino-functionalized MOF (amino-MIL-101(Al)), which shows an excellent MO (methyl orange) adsorption capacity. ${ }^{20}$ Therefore, we can conclude that both pore size and functional 
groups can affect the adsorption capacity. However, it is still a challenging work to assemble the porous MOFs influenced by host-guest interactions. Meanwhile, there are still quite a few examples that the uncoordinated oxygen atoms or uncoordinated carboxyl groups of MOFs act as functional groups in dye removal.

It is well known that the structures of the organic ligands play a critical role in the pore size of the coordination polymers, which further affects the adsorption ability. Therefore, we selected semi-flexible triscarboxylates (4-(3,5dicarboxylatobenzyloxy)benzoic acid) with five different imidazole bridging linkers as $\mathrm{N}$-donor ligands in the mixed-ligand system based on the following features: i) the free rotation of $-\mathrm{CH}_{2}-\mathrm{O}$ - can promote the flexibility of the triscarboxylate ligands to meet the requirements of coordination geometries of $\mathrm{Co}$ (II) ions for constructing the final structure, ii) the suitable size of carboxylate ligands makes it a feasible candidate to generate MOFs with an appropriate window, iii) the three carboxyl groups of the carboxylate ligands could exhibit more abundant coordination mode while coordinating with $\mathrm{Co}$ (II) ions, and iv) the location of three carboxyl groups makes it easier to generate uncoordinated oxygen atoms or uncoordinated carboxyl groups. Meanwhile, the different configurations and flexibility of five auxiliary N-donor ligands can be used to construct a series of intriguing frameworks with different pore sizes.
In this work, five MOFs have been successfully synthesized under solvothermal conditions, namely, $\left\{\left[\mathrm{Co}_{1.5}(\mathrm{HL})\left(4,4^{\prime}-\right.\right.\right.$ bidpe $\left.\left.)_{2}\left(\mathrm{H}_{2} \mathrm{O}\right)\right] \cdot 3 \mathrm{H}_{2} \mathrm{O}\right\}_{n} \quad(1), \quad\left\{\left[\mathrm{Co}_{3}(\mathrm{~L})_{2}\left(4,4^{\prime}-\text { bibp }\right)_{3}\left(\mu_{2}-\mathrm{O}\right)_{2}\right] \cdot 2 \mathrm{H}_{2} \mathrm{O}\right\}_{n}$ (2), $\{[\mathrm{Co}(\mathrm{HL})(1,3-\mathrm{bitl})] \cdot(1,4-\mathrm{Diox})\}_{n} \quad$ (3), $\quad\left[\mathrm{Co}_{2}(\mathrm{HL})_{2}(3,5 \text {-bipd })_{2}\right]_{n}$ (4), and $\left\{[\mathrm{Co}(\mathrm{HL})(\mathrm{tib})] \cdot 0.5 \mathrm{H}_{2} \mathrm{O} \cdot \mathrm{NMP}\right\}_{n}(5)$, which show different architectures from a $2 \mathrm{D}$ polyrotaxane network to an unprecedented 3D framework (Scheme 1). Meanwhile, all of the MOFs 1-5 have uncoordinated oxygen atoms or uncoordinated carboxyl groups. Moreover, three kinds of dyes with different sizes and functional groups were selected to investigate whether the uncoordinated $\mathrm{O}$ atoms and uncoordinated carboxyl groups of 1-5 can affect the adsorption capacity. In addition, the magnetic properties of complexes 2 and 4 were also investigated.

\section{Experimental section}

\section{Materials and physical measurements}

All reagents and solvents were obtained from Jinan Henghua Sci. \& Tec. Co. Ltd. and were used without further purification. The infrared spectrum was recorded as $\mathrm{KBr}$ pellets using a Nicolet 170SX spectrometer in the $4000-400 \mathrm{~cm}^{-1}$ region. Elemental analysis (C, H, and $\mathrm{N}$ ) was performed using a 2400 model Perkin-Elmer analyzer. Thermogravimetric analysis (TGA) was conducted using a Perkin-Elmer TGA-7
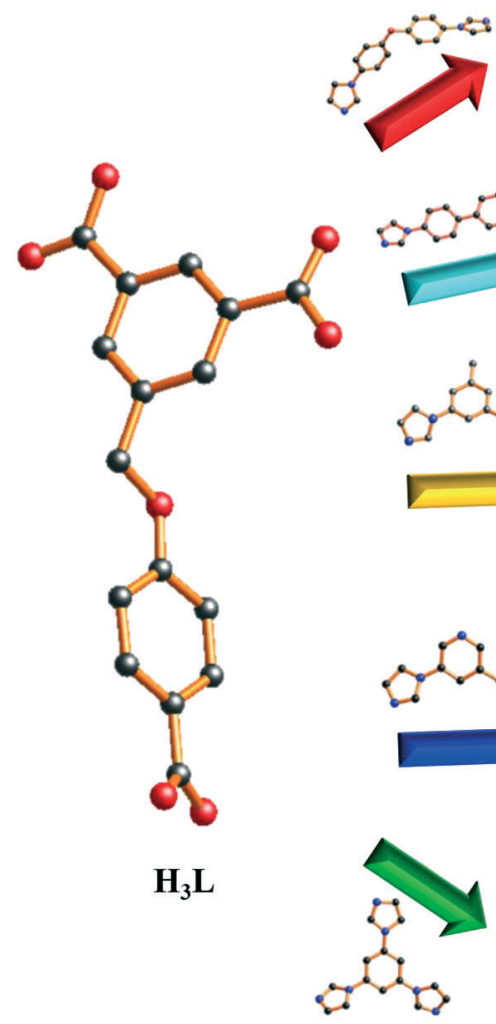
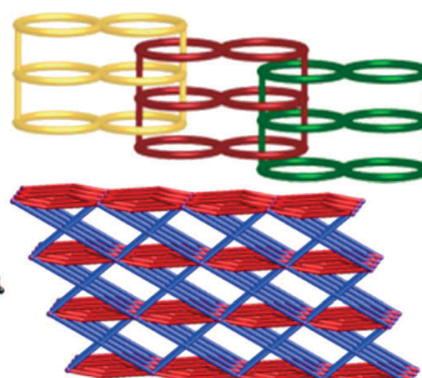

MOF-2
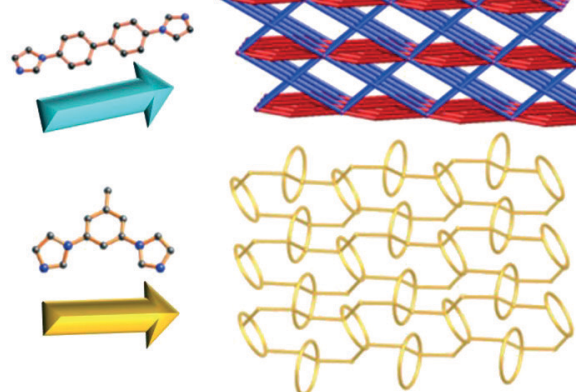

MOF-3
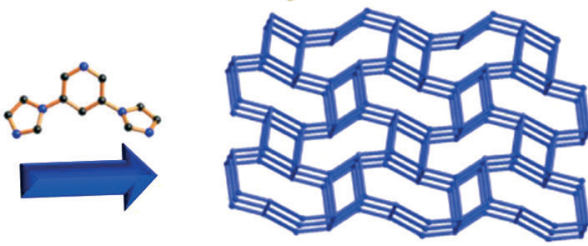

MOF-4

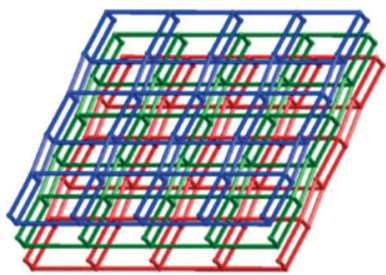

MOF-5

Scheme 1 Various polymeric structures of MOFs 1-5. 
thermogravimetric analyzer under $\mathrm{N}_{2}$ conditions from room temperature to $800{ }^{\circ} \mathrm{C}$ with a heating rate of $10{ }^{\circ} \mathrm{C} \mathrm{min}^{-1}$. $\mathrm{X}$-ray powder diffraction patterns (XRPD) were collected using a PANalytical X'Pert Pro diffractometer with $\mathrm{Cu}-\mathrm{K} \alpha$ radiation. Topological analysis was performed and confirmed using the TOPOS program and the Systre software. ${ }^{21-23}$

\section{Synthesis of $\left\{\left[\mathrm{Co}_{1.5}(\mathrm{HL})\left(4,4^{\prime} \text {-bidpe }\right)_{2}\left(\mathrm{H}_{2} \mathrm{O}\right)\right] \cdot 3 \mathrm{H}_{2} \mathrm{O}\right\}_{n}(1)$}

A mixture of $\mathrm{H}_{3} \mathrm{~L}(0.032 \mathrm{~g}, 0.1 \mathrm{mmol}), \mathrm{Co}\left(\mathrm{NO}_{3}\right)_{2} \cdot 6 \mathrm{H}_{2} \mathrm{O}(0.058$ $\mathrm{g}, 0.2 \mathrm{mmol})$ and 4,4'-bidpe $(0.090 \mathrm{~g}, 0.2 \mathrm{mmol})$ was dissolved in $9 \mathrm{~mL}$ of $\mathrm{DMF} / \mathrm{H}_{2} \mathrm{O}(1: 2, \mathrm{v} / \mathrm{v})$. The final mixture was placed in a Teflon-lined stainless steel vessel, heated to $130{ }^{\circ} \mathrm{C}$, maintained for 3 days, and then cooled (a descent rate of 5 ${ }^{\circ} \mathrm{C}^{-1}$ ) to room temperature. Violet block crystals 1 were obtained with a yield of $60 \%$ (based on Co). Anal. (\%) calcd. for $\mathrm{C}_{52} \mathrm{H}_{46} \mathrm{Co}_{1.5} \mathrm{~N}_{8} \mathrm{O}_{13}$ : C, 57.86; H, 4.29; N, 10.38. Found: C, 57.62; H, 4.25; N, 10.31. IR ( $\mathrm{KBr}$ pellet, $\mathrm{cm}^{-1}$ ): 3619 (w), 3346 (m), 3134 (w), 1602 (s), 1560 (m), 1516 (s), 1450 (w), 1419 (w), 1375 (m), 1357 (s), 1302 (w), 1246 (s), 1171 (m), 1124 (m), $1063(\mathrm{~m}), 1033$ (w), $1013(\mathrm{w}), 964(\mathrm{~m}), 936(\mathrm{w}), 874(\mathrm{w}), 837$ (m), $786(\mathrm{~m}), 741(\mathrm{~m}), 658(\mathrm{~m}), 532(\mathrm{~m}), 503(\mathrm{w}), 474(\mathrm{w})$.

\section{Synthesis of $\left\{\left[\mathrm{Co}_{3}(\mathrm{~L})_{2}\left(4,4^{\prime}-\mathrm{bibp}\right)_{3}\left(\mu_{2}-\mathrm{O}\right)_{2}\right] \cdot 2 \mathrm{H}_{2} \mathrm{O}\right\}_{n}(2)$}

The synthesis of 2 used the same condition as 1 except that 4,4'-bidpe was replaced by 4,4'-bibp. Brown crystals were collected with a yield of $52 \%$ (based on Co). Anal. (\%) calcd. for $\mathrm{C}_{54} \mathrm{H}_{46} \mathrm{Co}_{3} \mathrm{~N}_{10} \mathrm{O}_{19}$ : C, 49.29; $\mathrm{H}, 3.52 ; \mathrm{N}, 10.64$. Found: $\mathrm{C}, 49.22$; $\mathrm{H}, 3.49$; N, 10.61. IR ( $\mathrm{KBr}$ pellet, $\mathrm{cm}^{-1}$ ): 3619 (w), 3116 (m), 1590 (m), 1558 (m), 1516 (s), 1446 (m), 1385 (m), 1364 (m), 1310 (m), 1236 (m), 1163 (w), 1129 (w), 1061 (m), 960 (m), $936(\mathrm{w}), 823(\mathrm{~m}), 770(\mathrm{~m}), 703(\mathrm{w}), 648(\mathrm{~m}), 535(\mathrm{~m})$.

\section{Synthesis of $\{[\mathrm{Co}(\mathrm{HL})(1,3-\mathrm{bit})] \cdot(1,4-\mathrm{Diox})\}_{n}$ (3)}

A mixture of $\mathrm{H}_{3} \mathrm{~L}(0.032 \mathrm{~g}, 0.1 \mathrm{mmol}), \mathrm{Co}\left(\mathrm{NO}_{3}\right)_{2} \cdot 6 \mathrm{H}_{2} \mathrm{O}(0.058 \mathrm{~g}$, $0.2 \mathrm{mmol})$ and 1,3-bitl $(0.046 \mathrm{~g}, 0.2 \mathrm{mmol})$ was dissolved in $8 \mathrm{~mL}$ of 1,4 -diox $/ \mathrm{H}_{2} \mathrm{O}(1: 1, \mathrm{v} / \mathrm{v})$. The final mixture was placed in a Teflon-lined stainless steel vessel, heated to $130{ }^{\circ} \mathrm{C}$, maintained for 3 days, and then cooled (a descent rate of $5{ }^{\circ} \mathrm{C}$ $\mathrm{h}^{-1}$ ) to room temperature. Violet block crystals 3 were obtained with a yield of $51 \%$ (based on Co). Anal. (\%) calcd. for $\mathrm{C}_{33} \mathrm{H}_{30} \mathrm{CoN}_{4} \mathrm{O}_{9}$ : C, 57.81; H, 4.41; N, 8.17. Found: C, 57.77; H, 4.38; N, 8.12. IR (KBr pellet, $\mathrm{cm}^{-1}$ ): 3429 (w), 3126 (m), 2942 (w), 1683 (m), $1623(\mathrm{~m}), 1606$ (s), 1548 (s), 1508 (m), 1460 (w), 1439 (m), 1417 (w), 1378 (m), 1355 (s), 1320 (w), 1249 (s), 1168 (m), 1108 (m), 1081 (m), 1070 (m), 1004 (m), 946 (m), 910 (w), $889(\mathrm{w}), 871(\mathrm{~m}), 843(\mathrm{~m}), 825(\mathrm{w}), 777(\mathrm{~m}), 765(\mathrm{~m}), 733(\mathrm{~m})$, $684(\mathrm{~m}), 651(\mathrm{~m}), 631(\mathrm{w}), 614(\mathrm{w}), 554(\mathrm{w}), 532(\mathrm{w})$.

\section{Synthesis of $\left[\mathrm{Co}_{2}(\mathrm{HL})_{2}(3,5-\mathrm{bipd})_{2}\right]_{n}(4)$}

A mixture of $\mathrm{H}_{3} \mathrm{~L}(0.032 \mathrm{~g}, 0.1 \mathrm{mmol}), \mathrm{Co}\left(\mathrm{NO}_{3}\right)_{2} \cdot 6 \mathrm{H}_{2} \mathrm{O}(0.058$ $\mathrm{g}, 0.2 \mathrm{mmol})$ and 3,5-bipd (0.047 $\mathrm{g}, 0.2 \mathrm{mmol})$ was dissolved in $8 \mathrm{~mL}$ of $\mathrm{DMF} / \mathrm{H}_{2} \mathrm{O}(1: 1, \mathrm{v} / \mathrm{v})$. The final mixture was placed in a Teflon-lined stainless steel vessel, heated to $130{ }^{\circ} \mathrm{C}$, maintained for 3 days, and then cooled (a descent rate of 5
${ }^{\circ} \mathrm{C}^{-1}$ ) to room temperature. Violet block crystals 4 were obtained with a yield of $58 \%$ (based on Co). Anal. (\%) calcd. for $\mathrm{C}_{54} \mathrm{H}_{38} \mathrm{Co}_{2} \mathrm{~N}_{10} \mathrm{O}_{14}$ : C, 55.49; $\mathrm{H}, 3.27 ; \mathrm{N}, 11.98$. Found: $\mathrm{C}$, 55.45; H, 3.23; N, 11.95. IR (KBr pellet, $\mathrm{cm}^{-1}$ ): 3136 (m), 3053 (w), 3074 (w), 1681 (m), 1606 (m), 1560 (s), 1507 (m), 1447 (m), 1390 (s), 1319 (w), 1294 (w), 1263 (w), 1240 (s), 1215 (m), $1170(\mathrm{~m}), 1108$ (m), 1062 (m), 1010 (m), 958 (m), 936 (m), 901 (w), 881 (w), 853 (m), 837 (m), 807 (m), 777 (s), 731 (m), $692(\mathrm{w}), 651(\mathrm{~m}), 631(\mathrm{w}), 589(\mathrm{~m}), 541(\mathrm{w})$.

\section{Synthesis of $\left\{[\mathrm{Co}(\mathrm{HL})(\mathrm{tib})] \cdot 0.5 \mathrm{H}_{2} \mathrm{O} \cdot \mathrm{NMP}\right\}_{n}(5)$}

A mixture of $\mathrm{H}_{3} \mathrm{~L}(0.032 \mathrm{~g}, 0.1 \mathrm{mmol}), \mathrm{Co}\left(\mathrm{NO}_{3}\right)_{2} \cdot 6 \mathrm{H}_{2} \mathrm{O}(0.058 \mathrm{~g}$, $0.2 \mathrm{mmol})$ and tib (0.058 g, $0.2 \mathrm{mmol})$ was dissolved in $9 \mathrm{~mL}$ of $\mathrm{NMP} / \mathrm{H}_{2} \mathrm{O}(1: 1, \mathrm{v} / \mathrm{v})$. The final mixture was placed in a Teflonlined stainless steel vessel, heated to $130^{\circ} \mathrm{C}$, maintained for 3 days, and then cooled (a descent rate of $5^{\circ} \mathrm{C} \mathrm{h}^{-1}$ ) to room temperature. Red block crystals 5 were obtained with a yield of $53 \%$ (based on Co). Anal. (\%) calcd. for $\mathrm{C}_{72} \mathrm{H}_{64} \mathrm{Co}_{2} \mathrm{~N}_{14} \mathrm{O}_{17}$ : C, 57.07; H, 4.25; N, 12.94. Found: C, 57.02; H, 4.22; N, 12.89. IR (KBr pellet, $\mathrm{cm}^{-1}$ ): $3448(\mathrm{w}), 3134(\mathrm{w}), 2871(\mathrm{w}), 1685$ (s), 1616 (s), 1606 (m), 1569 (m), 1538 (m), 1507 (s), 1448 (m), 1381 (m), 1303 (w), 1286 (w), 1241 (m), 1168 (m), 1107 (w), 1075 (m), $1014(\mathrm{~m}), 933(\mathrm{~m}), 903(\mathrm{w}), 863(\mathrm{w}), 846(\mathrm{w}), 777(\mathrm{w}), 763(\mathrm{~m})$, $729(\mathrm{~m}), 682(\mathrm{~m}), 653(\mathrm{~m}), 533(\mathrm{w}), 503(\mathrm{w})$.

\section{X-ray crystallography}

X-ray crystallography data of complexes 1-5 were collected using a Bruker Apex Smart CCD diffractometer at 293(2) K with graphite-monochromated Mo-K $\alpha$ radiation $(\lambda=0.71073 \AA$ ) by using the $\omega-2 \theta$ scan mode. The structure was solved by direct methods using SHELXS-97. ${ }^{24}$ The non-hydrogen atoms were defined by the Fourier synthesis method. Positional and thermal parameters were refined by the full matrix least-squares method (on $F^{2}$ ) to convergence. ${ }^{25}$ Crystallographic data for complexes 1-5 are given in Table 1 . The selected bond lengths and angles for 1-5 are listed in Table S1 $\uparrow$ CCDC numbers for

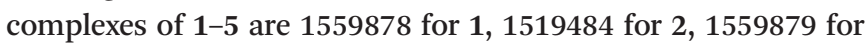
3, 1519483 for 4 and 1559880 for 5 .

\section{Results and discussion}

\section{Synthesis and characterization}

In this work, the synthesis of complexes 1-5 was constructed from $\mathrm{H}_{3} \mathrm{~L}$ and the related $\mathrm{Co}$ (II) salt in the presence of five N-donor (4,4'-bidpe, 4,4'-bibp, 1,3-bitl, 3,5-bipd and tib) bridging linkers under solvothermal conditions. These complexes, 1-5, are stable in the solid state upon extended exposure to air. Meanwhile, all of the complexes 1-5 have poor solubility in water and common organic solvent, but can be slightly soluble in very high polarity solvents.

\section{Structure description of $\left\{\left[\mathrm{Co}_{1.5}(\mathrm{HL})\left(4,4^{\prime} \text {-bidpe }\right)_{2}\left(\mathrm{H}_{2} \mathrm{O}\right)\right] \cdot 3 \mathrm{H}_{2} \mathrm{O}\right\}_{n}$} (1)

Single-crystal X-ray diffraction shows that compound 1 crystallizes in the triclinic space group $P \overline{1}$. In the 
Table 1 Summary of crystal data and structure refinement parameters for $1-5^{a}$

\begin{tabular}{|c|c|c|c|c|c|}
\hline Compound & 1 & 2 & 3 & 4 & 5 \\
\hline Formula weight & 2158.72 & 1728.26 & 685.54 & 1168.80 & 1515.23 \\
\hline Crystal system & Triclinic & Triclinic & Monoclinic & Triclinic & Triclinic \\
\hline$a(\AA)$ & $11.5476(14)$ & $10.8519(4)$ & $14.315(2)$ & $9.9822(3)$ & $9.8268(9)$ \\
\hline$b(\AA)$ & $14.6312(19)$ & $12.0078(4)$ & $12.4647(17)$ & $14.2046(4)$ & $13.2214(12)$ \\
\hline$c(\AA)$ & 15.3494(18) & $16.0618(6)$ & 18.515(3) & $18.0644(5)$ & $14.1027(13)$ \\
\hline$\gamma\left({ }^{\circ}\right)$ & $108.059(2)$ & $71.729(2)$ & 90 & $73.8020(10)$ & $108.809(2)$ \\
\hline$V\left(\AA^{3}\right)$ & $2413.0(5)$ & $1884.41(12)$ & $3108.0(7)$ & $2451.21(12)$ & $1668.7(3)$ \\
\hline$Z$ & 1 & 1 & 4 & 2 & 1 \\
\hline$D_{\text {calcd }}\left(\mathrm{Mg} \mathrm{m}^{-3}\right)$ & 1.486 & 1.523 & 1.465 & 1.584 & 1.508 \\
\hline$\mu\left(\mathrm{mm}^{-1}\right)$ & 0.599 & 0.736 & 0.615 & 0.760 & 0.582 \\
\hline Reflections collected & 18517 & 19575 & 26661 & 11116 & 12740 \\
\hline Final $R$ indices $[I>2 \sigma(I)]$ & $R_{1}=0.0484$ & $R_{1}=0.0307$ & $R_{1}=0.0398$ & $R_{1}=0.0733$ & $R_{1}=0.0386$ \\
\hline & $\mathrm{w} R_{2}=0.1279$ & $\mathrm{w} R_{2}=0.0935$ & $\mathrm{w} R_{2}=0.1146$ & $\mathrm{w} R_{2}=0.2228$ & $\mathrm{w} R_{2}=0.1138$ \\
\hline$R$ indices (all data) & $R_{1}=0.0776$ & $R_{1}=0.0346$ & $R_{1}=0.0482$ & $R_{1}=0.0 .1035$ & $R_{1}=0.0447$ \\
\hline & $\mathrm{w} R_{2}=0.1413$ & $\mathrm{w} R_{2}=0.0964$ & $\mathrm{w} R_{2}=0.1215$ & $\mathrm{w} R_{2}=0.2419$ & $\mathrm{w} R_{2}=0.1193$ \\
\hline Gof & 0.991 & 1.055 & 1.029 & 1.059 & 1.004 \\
\hline
\end{tabular}

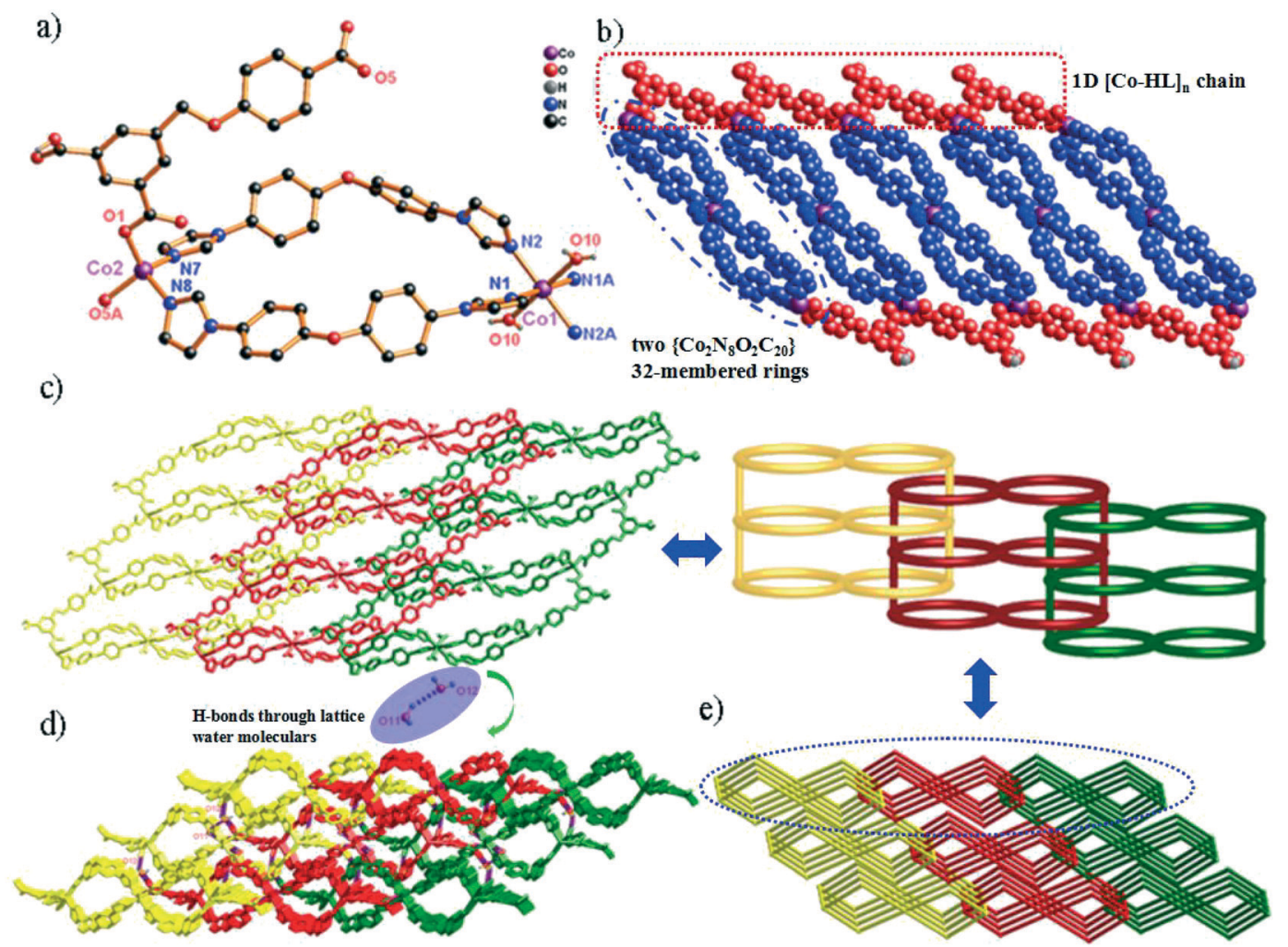

Fig. 1 (a) Coordination environment of the Co(II) ion in complex 1 (symmetry codes: i: $-x+2,-y+2,-z$; ii: $x, y-1, z$ ). (b) View of the 1D chain of 1 (blue spheres: 4,4'-bidpe ligands; red spheres: $\mathrm{HL}^{2-}$ ligands). (c) The rarely $1 \mathrm{D} \rightarrow 2 \mathrm{D}$ polyrotaxane networks and the $2 \mathrm{D}$ loop structure. (d) View of the 3D supramolecular structure through $\mathrm{H}$-bonds. (e) The 3-nodal $(2,4,4)$-connected 3D topology structure in complex 1.

asymmetric unit, there exist one and a half $\mathrm{Co}(\mathrm{II})$ centers (two types of $\mathrm{Co}(\mathrm{II})$ ions (Co1 and $\mathrm{Co} 2$ ); occupancy ratio: one for $\mathrm{Co} 2$ and a half for Co1), one $\mathrm{HL}^{2-}$ anion, two 4,4'bidpe ligands and one coordinated water molecule. As 
shown in Fig. 1a, the Co1 atom is six-coordinated, coordinated by four $\mathrm{N}$ atoms from four independent 4,4'-bidpe ligands and two $\mathrm{O}$ atoms from two coordination water molecules, displaying a slightly distorted octahedral coordination geometry. Meanwhile, the $\mathrm{Co} 2$ atom is fourcoordinated by two $\mathrm{O}$ atoms from two independent $\mathrm{HL}^{2-}$ ligands and two $\mathrm{N}$ atoms from two different 4,4'-bidpe ligands, forming a slightly distorted tetrahedral coordination geometry. The bond lengths of $\mathrm{Co}-\mathrm{O}$ and $\mathrm{Co}-\mathrm{N}$ vary between 1.941(2)-2.118(2) $\AA$ and 2.012(3)-2.159(3) $\AA$, respectively.

In complex 1, two adjacent $\mathrm{Co} 2$ ions are connected by a partially deprotonated $\mathrm{HL}^{2-}$ ligand, which shows a $\mu_{2}-\left(\kappa^{1}-\kappa^{0}\right)-\left(\kappa^{1}-\kappa^{0}\right)$ coordination mode (Scheme 2, mode I), constructing a $1 \mathrm{D}[\mathrm{Co}-\mathrm{HL}]_{n}$ linear chain. Interestingly, three neighbouring Co(II) ions (one Co1 and two Co2) are bridged through four 4,4'-bidpe ligands, forming two same loops ( $\left\{\mathrm{Co}_{2} \mathrm{~N}_{8} \mathrm{O}_{2} \mathrm{C}_{20}\right\}$ 32-membered ring). The adjacent loop and $[\mathrm{Co}-\mathrm{HL}]_{n}$ chain connected each other by sharing the same Co2 ion, further constructing a 1D loop chain (Fig. 1b). The parallel 1D loop chains interconnect with each other, finally forming a rare $1 \mathrm{D} \rightarrow 2 \mathrm{D}$ polyrotaxane layer (Fig. 1c). Furthermore, the 2D polyrotaxane layer further interacted with the neighbouring polyrotaxane layer through $\mathrm{H}$-bonds, finally resulting in a 3D supramolecular structure (Fig. 1d). Moreover, with the lattice $\mathrm{H}_{2} \mathrm{O}$ molecules being omitted, the calculation using PLATON shows that the void volume of 1 is $5.8 \%$ of the crystal volume $\left(140.1 \AA^{3}\right.$ out of the $2413.0 \AA^{3}$ unit cell volume). ${ }^{26}$ From a topological view, the whole structure exhibits a 3-nodal $(2,4,4)$-connected $3 \mathrm{D}$ supramolecular structure (Fig. 1e).
Structure description of $\left\{\left[\mathrm{Co}_{3}(\mathrm{~L})_{2}\left(4,4^{\prime}-\mathrm{bibp}\right)_{3}\left(\mu_{2}-\mathrm{O}\right)_{2}\right] \cdot 2 \mathrm{H}_{2} \mathrm{O}\right\}_{n}$ (2)

Complex 2 exhibits a 3D Co(II) metal-organic framework with trinuclear metal-oxygen clusters. Complex 2 crystallizes in the triclinic system space group $P \overline{1}$. In its asymmetric unit, there are two types of Co(II) ions (two Co1 ions and one Co2 ion), two completely deprotonated $\mathrm{L}^{3-}$ anions, three 4,4'-bibp auxiliary ligands and two $\mu_{2}-\mathrm{O}$. As shown in Fig. 2a, the Co1 atom is hexa-coordinated by two $\mathrm{N}$ atoms from two individual 4,4'-bibp ligands, three $\mathrm{O}$ atoms from three different $\mathrm{L}^{3-}$ ligands and one $\mathrm{O}$ atom from $\mu_{2}-\mathrm{O}$. Meanwhile, the $\mathrm{Co} 2$ atom also is six-coordinated, coordinated by two $\mathrm{N}$ atoms from two independent 4,4'-bibp ligands, two $\mathrm{O}$ atoms from two $\mathrm{L}^{3-}$ ligands and two $\mathrm{O}$ atom from two $\mu_{2}-\mathrm{O}$. Three crystallographically distinct $\operatorname{Co}$ (II) ions are bound together by two $\mu_{2}-\left(\kappa^{1}-\kappa^{1}\right)$ carboxylate groups and two $\mu_{2}-\mathrm{O}$ to form trinuclear $\left[\mathrm{Co}_{3}\left(\mu_{2}-\right.\right.$ $\left.\mathrm{O})_{2}(\mathrm{COO})_{2}\right]$ clusters, which can be defined as SBUs. The bond lengths of Co-O and Co-N are in the range of 2.049(12)-

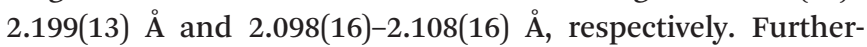
more, the intermetallic distance separated by the $\mu_{2}-\mathrm{O}$ and $\mu_{2}-\left(\kappa^{1}-\kappa^{1}\right)$ carboxylate group is $3.756(3) \AA$ (Co1 $\cdots$ Co2 $)$.

In complex $2, \mathrm{H}_{3} \mathrm{~L}$ ligands are completely deprotonated with the $\mu_{4}-\left(\kappa^{1}-\kappa^{1}\right)-\left(\kappa^{1}-\kappa^{0}\right)-\left(\kappa^{1}-\kappa^{0}\right)$ coordination mode (Scheme 2, mode II). The completely deprotonated $\mathrm{H}_{3} \mathrm{~L}$ ligands connect the adjacent three $\left[\mathrm{Co}_{3}\left(\mu_{2}-\mathrm{O}\right)_{2}(\mathrm{COO})_{2}\right]^{4+}$ SBUs to construct a $2 \mathrm{D}$ kgd network with a point symbol of $\left(4^{3}\right)^{2}\left(4^{6}\right.$ $\left.\cdot 6^{8} \cdot 8^{3}\right)$. When the $\mathrm{H}_{3} \mathrm{~L}$ ligands are ignored, the neighbouring two $\left[\mathrm{Co}_{3}\left(\mu_{2}-\mathrm{O}\right)_{2}(\mathrm{COO})_{2}\right]$ SBUs are connected by $\mathrm{N}$-donor ligands, showing a 2D sql network with an $-\mathrm{A}-\mathrm{B}-\mathrm{A}-$ fashion (Fig. 2b and $\mathrm{S} 1 \dagger$ ). Furthermore, two different networks

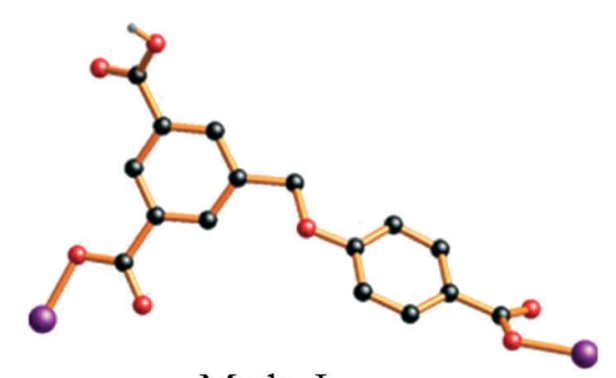

Mode I

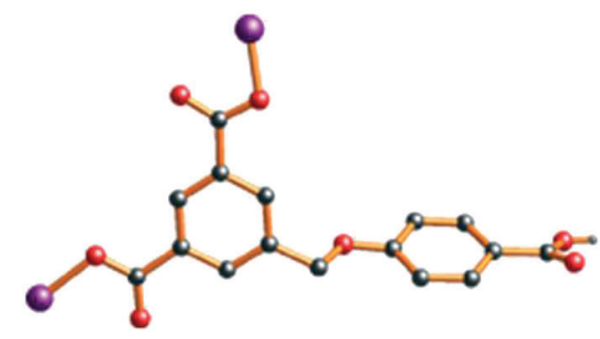

Mode III

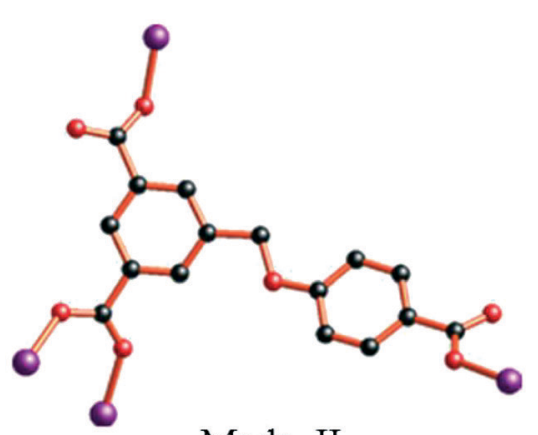

Mode II

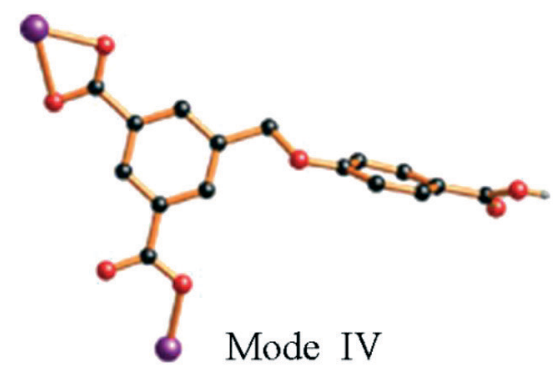

Scheme 2 Diverse coordination modes of $\mathrm{H}_{3} \mathrm{~L}$ in MOFs 1-5. 


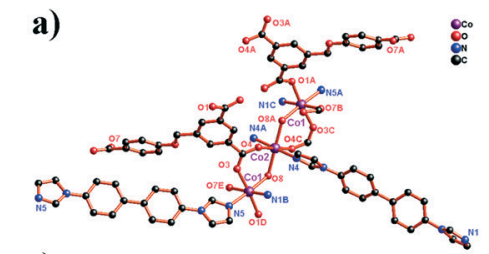

c)

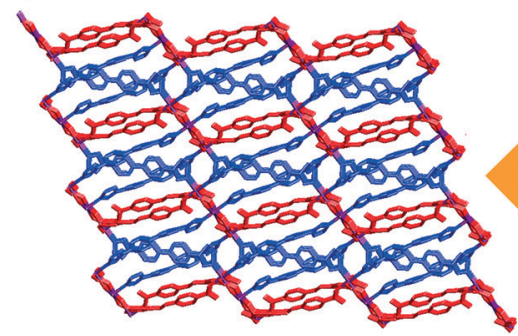

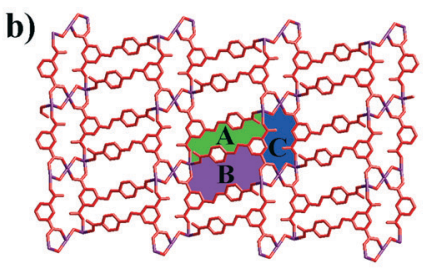

d)
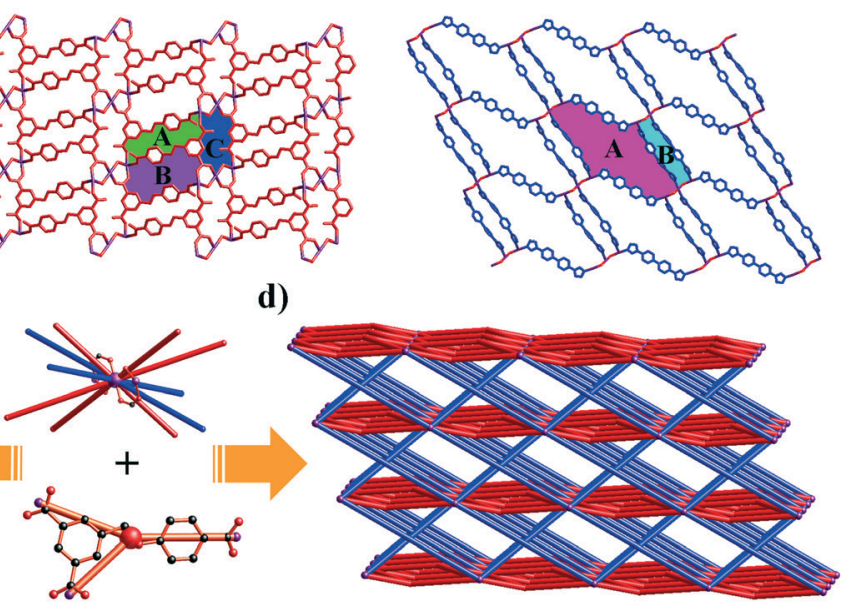

Fig. 2 (a) Coordination environment of the Co(II) ion in complex 2 (symmetry codes: i: $x+1, y, z$; ii: $-x+1,-y,-z+2$; iii: $-x,-y$, $-z+1$; iv: $x-1, y$, $z)$. (b) View of the $2 \mathrm{D} \mathrm{kgd}\left[\mathrm{Co}_{3}\left(\mathrm{~L}^{3-}\right)_{2}\right]_{n}$ network and $2 \mathrm{D}$ sql $\left[\mathrm{Co}_{3}\left(4,4^{\prime} \text {-bibp }\right)_{2}\right]_{n}{ }^{6 n+}$ network (blue spheres: $4,4^{\prime}$-bibp ligands; red spheres: $\mathrm{L}^{3-}$ ligands). (c) The 3D framework of 2. (d) View of the unprecedented 2-nodal $(3,10)$-connected 3D framework with a $\left(4^{3}\right)^{2}\left(4^{6} \cdot 6^{32} \cdot 8^{3}\right)\left(4^{3}\right)^{2}$ topology.

selectively connect each other, forming a stable $3 \mathrm{D}$ framework (Fig. 2c). The effective free volume of 2 was $1.8 \%$ of the crystal volume (34.3 $\AA^{3}$ out of the $1884.4 \AA^{3}$ unit cell volume), calculated using PLATON. ${ }^{26}$

From a topological view, the trinuclear $\left[\mathrm{Co}_{3}\left(\mu_{2}-\mathrm{O}\right)_{2}(\mathrm{COO})_{2}\right]$ cluster can be viewed as a ten-connector, while the $\mathrm{H}_{3} \mathrm{~L}$ ligands can be viewed as a three-connector. Thus, the 3D framework acquired can be simplified as an unprecedented 2-nodal $(3,10)$-connected metal-organic framework with a $\left(4^{3}\right)^{2}\left(4^{6} \cdot 6^{32} \cdot 8^{3}\right)\left(4^{3}\right)^{2}$ topology (Fig. 2d).

Structure description of $\{[\mathrm{Co}(\mathrm{HL})(1,3-\mathrm{bitl})] \cdot(1,4-\mathrm{Diox})\}_{n}(3)$

The crystal structure determined by single-crystal X-ray diffraction reveals that complex 3 crystallizes in the monoclinic system, space group $P 2_{1} / c$. The asymmetric unit of 3 contains one $\mathrm{Co}(\mathrm{II})$ cation, one $\mathrm{HL}^{2-}$ ligand and one 1,3-bitl N-donor ligand. As depicted in Fig. 3a, the coordination environment around the $\mathrm{Co}$ (II) atom is composed of two $\mathrm{O}$ atoms from two different $\mathrm{HL}^{2-}$ ligands and two $\mathrm{N}$ atoms from two independent 1,3-bitl ligands, exhibiting a distorted tetrahedral geometry. The $\mathrm{Co}-\mathrm{O}$ bond distances are 1.9643(14) (Co1-O2) and $1.9642(14) \AA\left(\mathrm{Co}^{-}-\mathrm{O} 4^{\mathrm{i}}\right)$, and the $\mathrm{Co}-\mathrm{N}$ bond distances are 2.0210(17) (Co1-N1) and 2.0412(16) $\mathrm{A}\left(\mathrm{Co} 1-\mathrm{N} 4^{\mathrm{ii}}\right)$, respectively.

Similar to 1 , adjacent $\mathrm{Co}(\mathrm{II})$ ions are also bridged by the partially deprotonated $\mathrm{HL}^{2-}$ ligands (coordination mode: $\mu_{2}-\left(\kappa^{1}-\kappa_{0}\right)-\left(\kappa^{1}-\kappa^{0}\right)$; Scheme 2 , mode III) to form a $1 \mathrm{D}$ $[\mathrm{Co}-\mathrm{HL}]_{n}$ liner chain in 3. However, in 3 , two neighbouring Co1 ions are bridged through two 1,3-bitl ligands, forming an independent loop ( $\left\{\mathrm{Co}_{2} \mathrm{~N}_{8} \mathrm{C}_{10}\right\}$ 20-membered ring). These independent $\left\{\mathrm{Co}_{2} \mathrm{~N}_{8} \mathrm{C}_{10}\right\}$ loops are connected by $\mathrm{HL}^{2-}$ ligands, constructing a 2D network (Fig. 3b). The adjacent $2 \mathrm{D}$ networks further interacted with each other through H-bonds, constructing a 3D supramolecular structure (Fig. 3c and S2 $\dagger$ ). Furthermore, with the guest 1,4-diox molecules being omit- ted, the calculation using PLATON shows that the void volume of 3 is $20.8 \%$ of the crystal volume $\left(645.4 \AA^{3}\right.$ out of the $3108.0 \AA^{3}$ unit cell volume). ${ }^{26}$ From a topological view, the $\mathrm{Co}$ (II) ion can be considered as a 4-connected node, and two "V"-shaped spacers ( $\mathrm{HL}^{2-}$ and 1,3-bitl) can be considered as 2 -connected node. Thus, the final 3D supramolecular framework can be classified as a $(2,2,4)$-connected network (Fig. 3d).

Structure description of $\left[\mathrm{Co}_{2}(\mathrm{HL})_{2}(3,5 \text {-bipd })_{2}\right]_{n}(4)$

In order to investigate the effect of auxiliary ligand configuration on the final structure, the 3,5-bipd ligand was employed in the mixed system. And another framework 4 was obtained. It crystallizes in the triclinic space group $P \overline{1}$, and the asymmetric unit consists of two different types of $\mathrm{Co}$ (II) ions (Co1 and $\mathrm{Co} 2$ ), two $\mathrm{HL}^{2-}$ ligands and two 3,5-bipd ligands. As shown in Fig. 4a, the environment around Co1 can be described as a slightly distorted octahedral geometry, coordinated by three $\mathrm{O}$ atoms from two different $\mathrm{HL}^{2-}$ ligands and three $\mathrm{N}$ atoms from three independent 3,5-bipd ligands. Interestingly, Co2 shows the same coordination environment as $\mathrm{Co} 1$. The $\mathrm{Co}-\mathrm{O}$ bond distances are in the range of 2.016(3)-2.387(4) $\AA$, and the Co- $\mathrm{N}$ bond distances are in the range of 2.079(3)-2.262(3) $\AA$ Å, respectively.

The $\mathrm{H}_{3} \mathrm{~L}$ ligand in complex 4 is also partially deprotonated and exhibits a $\mu_{2}-\left(\kappa^{1}-\kappa^{1}\right)-\left(\kappa^{1}-\kappa^{0}\right)$ coordination mode (Scheme 2, mode IV). Three adjacent Co(II) ions are bridged by $\mu_{3}$-bipd ligand to generate 3 -connected fes $2 \mathrm{D}$ networks with two different windows (Fig. 4b). These 2D networks are further linked by $\mathrm{HL}^{2-}$ ligands to generate a more complicated 3D framework (Fig. 4c). The effective free volume of 4 was $2.1 \%$ of the crystal volume $\left(51.3 \AA^{3}\right.$ out of the $2451.2 \AA^{3}$ unit cell volume), calculated using PLATON. ${ }^{26}$ 
a)
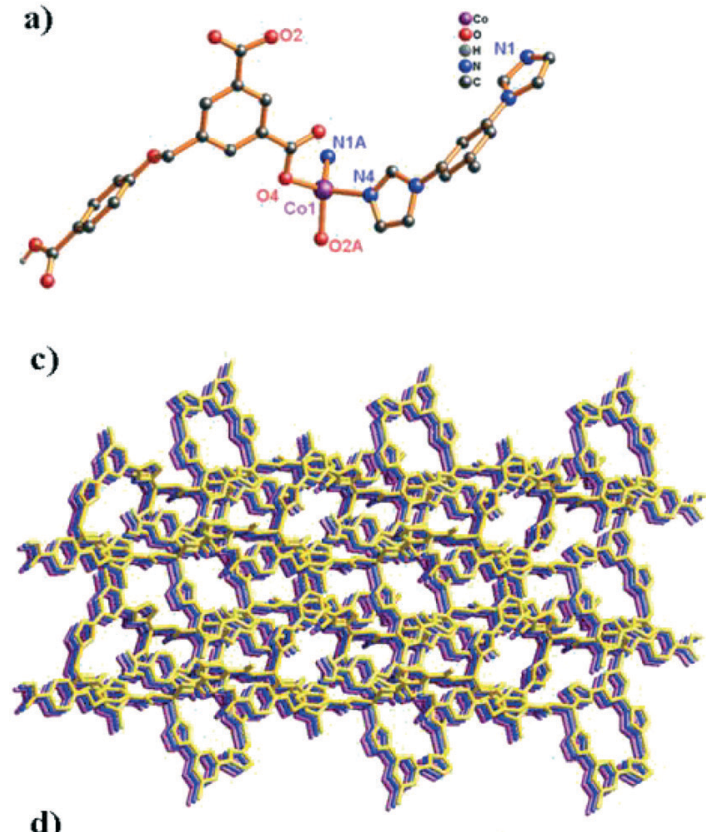

d)

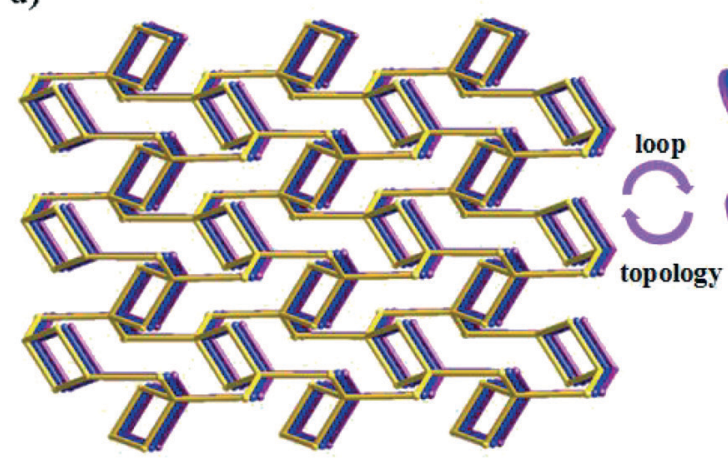

b)
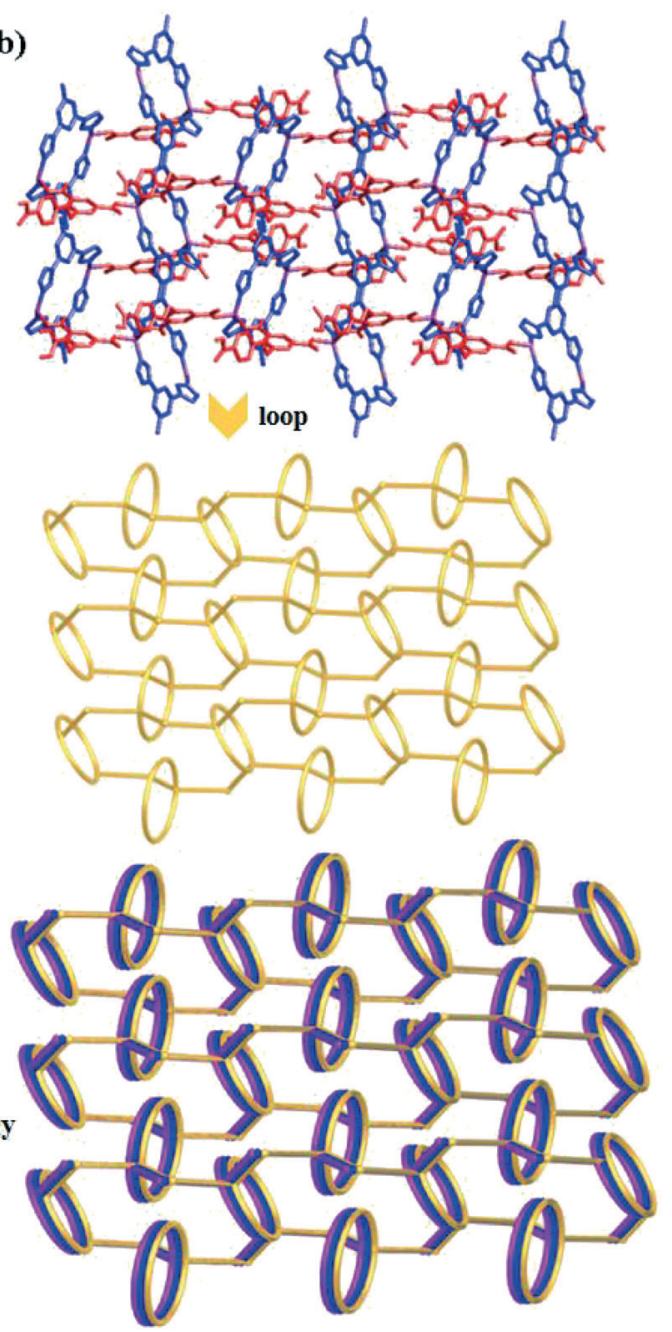

Fig. 3 (a) Coordination environment of the Co(II) ion in complex 3 (symmetry codes: i: $x,-y+1 / 2, z+1 / 2 ;$ ii: $-x+2,-y+1,-z+2$; iii: $x,-y+1 / 2, z$ $-1 / 2$ ). (b) View of the 2D topology network and 2D loop network in complex 3 (blue spheres: 1,3-bitl ligands; red spheres: $\mathrm{HL}^{2-}$ ligands). (c) The 2D $\rightarrow$ 3D supramolecular networks through $\mathrm{H}$-bonds. (d) View of the $(2,2,4)$-connected 3D supramolecular framework.

From the viewpoint of structural topology, the whole 3D structure exhibits an unprecedented 2-nodal $(3,5)$-connected 3D framework with a $\left(4 \cdot 6^{2}\right)\left(4 \cdot 6^{6} \cdot 8^{3}\right)$ topology (Fig. 4d).

Structure description of $\left\{[\mathrm{Co}(\mathrm{HL})(\mathrm{tib})] \cdot 0.5 \mathrm{H}_{2} \mathrm{O} \cdot \mathrm{NMP}\right\}_{n}(5)$

When the 3,5-bipd ligand was replaced by another tris(imidazole) linker (tib), an unprecedented 3D supramolecular framework was obtained. Structure analysis reveals that complex 5 crystallizes in the triclinic system, space group $P \overline{1}$. In the asymmetric unit, there exists one crystallographically unique $\mathrm{Co}$ (II) atom, one $\mathrm{HL}^{2-}$ ligand and one tib $\mathrm{N}$-donor ligand. As shown in Fig. 5a, the Co(II) center shows a rare fivecoordinated environment, ligated by two $\mathrm{O}$ atoms from two different $\mathrm{HL}^{2-}$ ligands and three $\mathrm{N}$ atoms from three independent tib ligands. The Co-O bond distances are 2.0686(16) (Co1-O1) and 2.0917(17) $\AA$ (Co1-O3 $\left.{ }^{\mathrm{i}}\right)$, and the Co-N bond distances are 2.1185(17) (Co1-N1), 2.1207(18) (Co1-N4 ${ }^{\mathrm{iii}}$ ), and 2.1127(18) $\AA$ (Co1-N6 ${ }^{\mathrm{ii}}$ ), respectively.
In complex 5, the $\mathrm{H}_{3} \mathrm{~L}$ ligand shows the same coordination mode as 3 (Scheme 2, mode III). Two adjacent Co(II) atoms are connected by the partially deprotonated $\mathrm{HL}^{2-}$ ligand, which constructs a $1 \mathrm{D}[\mathrm{Co}-\mathrm{HL}]_{n}$ chain. Meanwhile, the $\mu_{3}$-tib $\mathrm{N}$-donor ligand bridging three neighbouring $\mathrm{Co}$ (II) atoms further constructed a 1D $[\mathrm{Co}-\mathrm{tib}]_{n}$ ladder chain with a $5.9960(27) \times 6.2379(25) \AA^{2}$ window. Furthermore, those two different chains interact with each other through Co1 ions, forming an unprecedented 2-nodal (3,5)-connected 2D network (Fig. 5b). Two adjacent 2D networks further connect each other through $\mathrm{H}$-bonds (O6- $\mathrm{H} 6 \cdots \mathrm{O} 2)$, constructing another stable 3D supramolecular framework (Fig. $5 \mathrm{c}$ and $\mathrm{S} 3 \dagger$ ). Furthermore, with the guest $\mathrm{H}_{2} \mathrm{O}$ and NMP molecules being omitted, the calculation using PLATON shows that the void volume of 5 is $23.5 \%$ of the crystal volume $\left(391.8 \AA^{3}\right.$ out of the $1668.7 \AA^{3}$ unit cell volume). ${ }^{26}$ Based on the concept of topology, the whole structure can be classified into an unprecedented 2-nodal $(3,5)$-connected 3D supramolecular framework with a $\left(4^{2} \cdot 6^{7} \cdot 8\right)\left(4^{2} \cdot 6\right)$ topology (Fig. 5d). 
a)

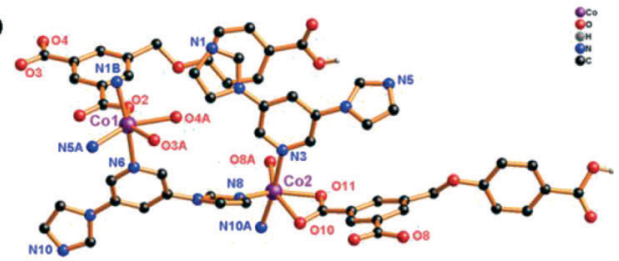

b)
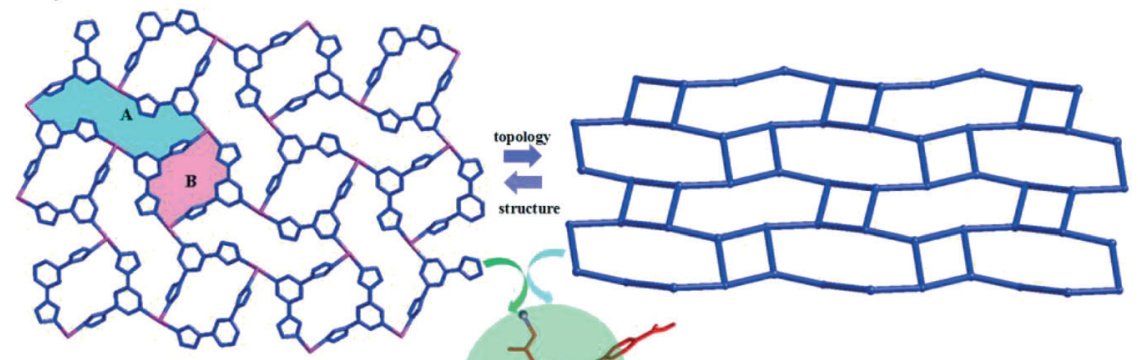

c) d)
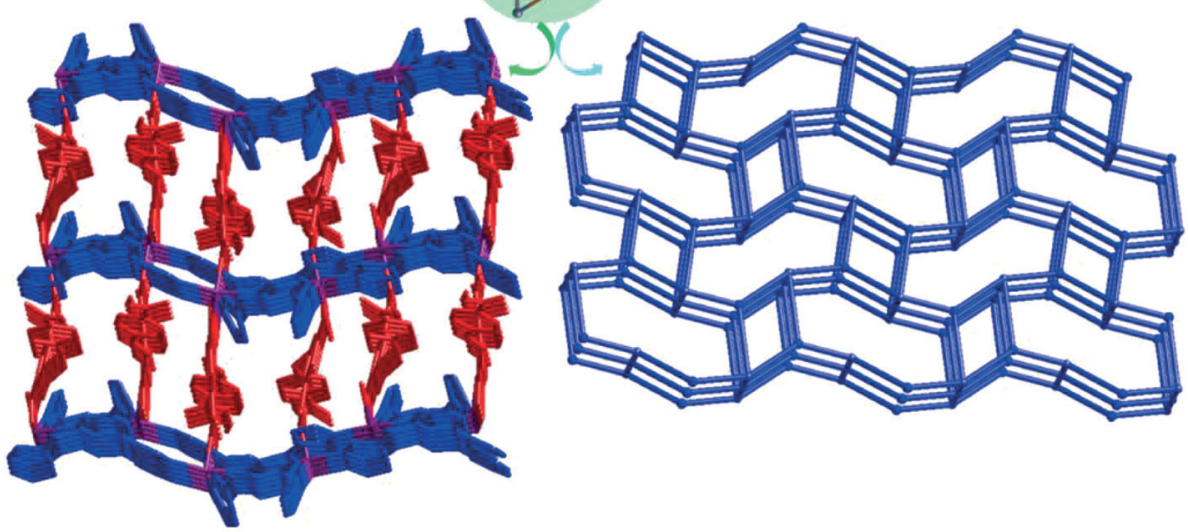

Fig. 4 (a) Coordination environment of the Co(I) ion in complex 4 (symmetry codes: i: $x+1, y, z$; ii: $-x+1,-y+1,-z+1$; iii: $x-1, y, z$; iv: $x, y, z-$ 1). (b) View of the 3-connected fes 2D [Co(3,5-bipd) $]_{n}{ }^{2 n+}$ network in 4. (c) The 3D framework of complex 4 (blue spheres: 3,5-bipd ligands; red spheres: $\mathrm{HL}^{2-}$ ligands). (d) View of the unprecedented 2-nodal $(3,5)$-connected 3D framework with the Schläfli symbol $\left(4 \cdot 6^{2}\right)\left(4 \cdot 6^{6} \cdot 8^{3}\right)$.

\section{Structural comparison and discussion}

As is well known, the flexibility of the carboxylate ligands, the central metals and the configuration of $\mathrm{N}$-donor ligands play a key role in the construction of the structures of MOFs. As shown in Scheme 2 and Fig. $\mathrm{S} 4, \uparrow \mathrm{H}_{3} \mathrm{~L}$ exhibits versatile coordination modes and different dihedral angles between the two phenyl rings in $\mathrm{H}_{3} \mathrm{~L}$, which further results in a series of novel topologies. Although complexes 1, 3 and 5 exhibit the same coordination mode $\left(\mu_{2}-\left(\kappa^{1}-\kappa^{0}\right)-\left(\kappa^{1}-\kappa^{0}\right)\right)$, the dihedral angle of these complexes are different $\left(42.17(3)^{\circ}\right.$ for $1,68.72(2)^{\circ}$ for 3 and $61.19(2)^{\circ}$ for 5). Meanwhile, compared with 3 and 5, the two coordinated carboxyl groups are obtained from two different phenyl rings in 1 . In complex 2 , the $\mathrm{H}_{3} \mathrm{~L}$ ligands show a completely deprotonated mode $\left(\mu_{4}-\left(\kappa^{1}-\kappa^{1}\right)-\left(\kappa^{1}-\kappa^{0}\right)-\left(\kappa^{1}-\right.\right.$ $\left.\kappa^{0}\right)$ ) with a $22.90(1)^{\circ}$ dihedral angle. In complex 4 , the $\mathrm{H}_{3} \mathrm{~L}$ ligands show a different partially deprotonated coordination mode $\left(\mu_{2}-\left(\kappa^{1}-\kappa^{1}\right)-\left(\kappa^{1}-\kappa^{0}\right)\right)$, and the dihedral angle between two phenyl rings is the biggest one $\left(75.98(3)^{\circ}\right)$. Interestingly, both the biggest (4) and the smallest (2) dihedral angle of the $\mathrm{H}_{3} \mathrm{~L}$ ligands show a 3D framework through connecting with
$\mathrm{N}$-donor ligands. Therefore, we considered that the flexibility of $\mathrm{H}_{3} \mathrm{~L}$ ligands could deeply influence the final architecture.

As is well known, the different lengths and configurations of $\mathrm{N}$-donor ligands greatly influence the final structure. ${ }^{27}$ Except for 1 being a semi-flexible-auxiliary ligand, the $\mathrm{N}$-donor ligands can be seen as rigid-auxiliary ligands in complexes $\mathbf{2 - 5}$. Therefore, only complex 1 shows a rare $1 \mathrm{D} \rightarrow 2 \mathrm{D}$ polyrotaxane network, and complexes 2-5 show an unprecedented 3D framework, a 2D network, a 3D unprecedented framework and a 2D unprecedented network, respectively. Meanwhile, influenced by the configuration of the N-donor ligands, complexes 1, 3, 4 and 5 have one uncoordinated carboxyl groups, while complex 2 have uncoordinated oxygen atoms. Moreover, the pore sizes of complexes 1-5 are different due to the configuration of the $\mathrm{N}$-donor ligands. Thus, complexes 1-5 can be used to investigate the adsorption capacity, which is affected by their different structures.

\section{Thermal analyses}

To estimate the thermal stabilities of compounds $\mathbf{1 - 5}$, their thermal behaviors were investigated by thermogravimetric 
a)

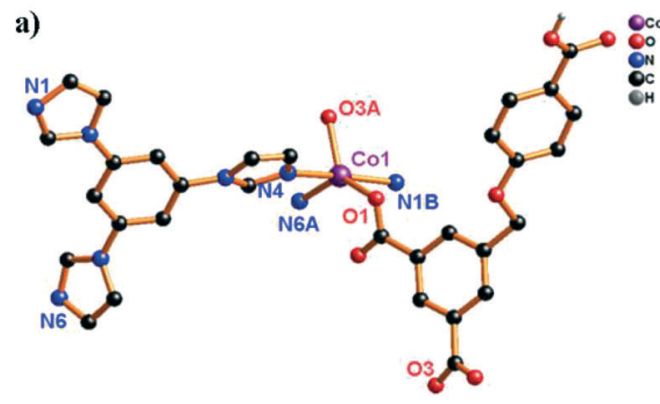

c)

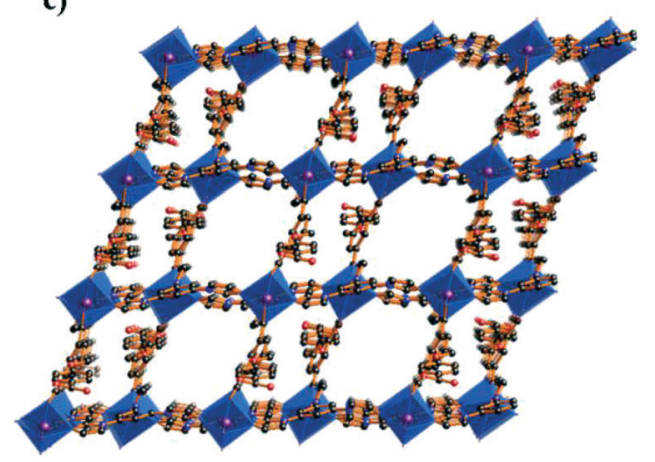

b)

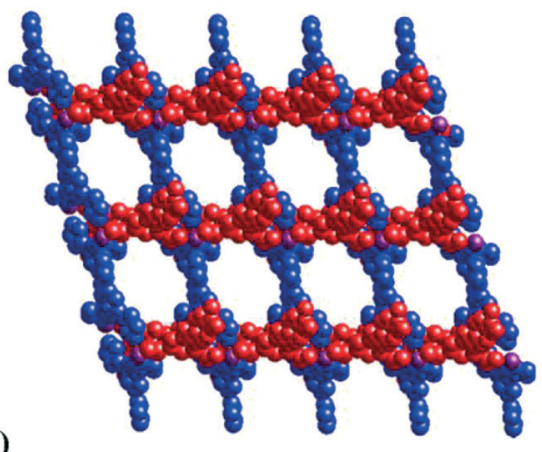

d)

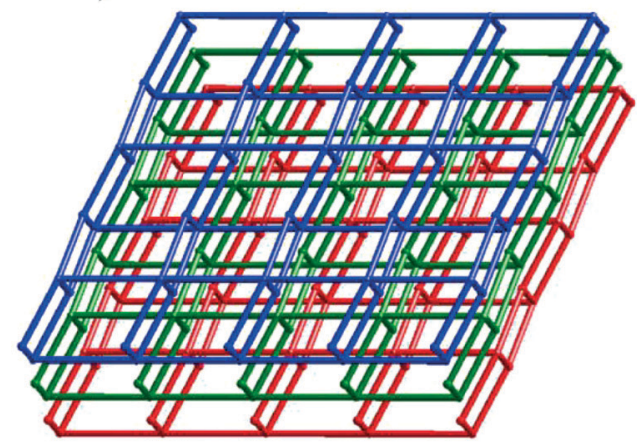

Fig. 5 (a) Coordination environment of the Co(II) ion in complex 5 (symmetry codes: i: $x+1, y, z$;ii: $-x+1,-y+1,-z+2$; iii: $x, y-1, z$; iv: $x-1, y$, $z$ ). (b) View of the unprecedented 2-nodal $(3,5)$-connected 2D network in 5 (blue spheres: tib ligands; red spheres: $\mathrm{HL}^{2-}$ ligands). (c) The $2 \mathrm{D} \rightarrow 3 \mathrm{D}$ supramolecular framework through $\mathrm{H}$-bonds. (d) The 3D topology structure of 5 with the point symbol $\left(4^{2} \cdot 6^{7} \cdot 8\right)\left(4^{2} \cdot 6\right)$.

analyses (TGA) under a $\mathrm{N}_{2}$ atmosphere at a heating rate of 10 ${ }^{\circ} \mathrm{C} \min ^{-1}$ (Fig. S5 $\dagger$ ). The TG curves of 1 and 2 exhibit a good resemblance. The first weight loss was from room temperature to $240{ }^{\circ} \mathrm{C}$ for 1 (obsd: $6.59 \%$, calcd: $6.67 \%$ ) and from 100-240 ${ }^{\circ} \mathrm{C}$ for 2 (obsd: $2.02 \%$, calcd: $2.08 \%$ ), corresponding to the removal of the lattice $\mathrm{H}_{2} \mathrm{O}$ and/or coordinated $\mathrm{H}_{2} \mathrm{O}$ molecules. The second weight loss corresponds to the loss of the organic ligands at $\mathrm{ca} .335^{\circ} \mathrm{C}$ for 1 and $\mathrm{ca} .270{ }^{\circ} \mathrm{C}$ for 2 . The remaining weight corresponds to the formation of $\mathrm{CoO}$ (obsd: $32.65 \%$ calcd: $10.42 \%$ for 1 ; obsd: $42.49 \%$, calcd: $13.02 \%$ for 2 ). There is no lattice solvent molecule in 3 and 4 , therefore, the TG curves exhibit plateaus before $305{ }^{\circ} \mathrm{C}$ for 3 and $360{ }^{\circ} \mathrm{C}$ for 4 , and then the pyrolysis of the framework took place. The remaining weight corresponds to the formation of $\mathrm{CoO}$ (obsd: 29.19\%, calcd: $10.94 \%$ for 3; obsd: $28.26 \%$, calcd: $12.84 \%$ for 4 ). For complex 5, the first weight loss in the temperature range of $180-240{ }^{\circ} \mathrm{C}$ is consistent with the removal of the lattice NMP and $\mathrm{H}_{2} \mathrm{O}$ molecules (obsd: $12.42 \%$, calcd: $12.82 \%$ ). The second weight loss corresponds to the loss of the organic ligands at $\mathrm{ca} .350^{\circ} \mathrm{C}$. The remaining weight corresponds to the formation of $\mathrm{CoO}$ (obsd: $37.31 \%$, calcd: $9.90 \%$ ). The larger CoO remaining weight (obsd) may be caused by the incomplete decomposition of compounds 1-5 under $800{ }^{\circ} \mathrm{C}$.

\section{UV-visible spectra of complexes 1-5}

Based on the different colors of complexes 1-5, their solid state UV-vis adsorption spectra were measured at room tem- perature (Fig. S6 $†$ ). The spectra of complexes 1-5 show two wide absorption bands in the range of 235-420 $\mathrm{nm}$ and 430$640 \mathrm{~nm}$, respectively. And the absorption band from 235-420 nm should be considered as $\pi-\pi^{*}$ transitions of the ligands. ${ }^{28}$ Another absorption band from 430-625 $\mathrm{nm}$ can be ascribed to the spin-allowed $\mathrm{d}-\mathrm{d}$ electronic transitions of the $\mathrm{d}^{7}\left(\mathrm{Co}^{2+}\right)$ cation. $^{29}$ The different colors of complexes 1-5 are caused by the absorption band and absorption intensity.

\section{Magnetic properties of 2 and 4}

The magnetic susceptibility measurements were taken in the temperature range of $2-300 \mathrm{~K}$ under an applied field of 1000 Oe. For complex 2, as shown in Fig. 6, the $\chi_{M} T$ value is 9.98 at $300 \mathrm{~K}$, which is almost twice higher than the expected value for three high-spin Co(II) ions $\left(5.63 \mathrm{~cm}^{3}\right.$ $\left.\mathrm{K} \mathrm{mol}^{-1}, S=3 / 2, g=2.0\right)$. When the temperature is lowered, the $\chi_{\mathrm{M}} T$ value decreased gradually and reached the value of $0.68 \mathrm{~cm}^{3} \mathrm{~K} \mathrm{~mol}^{-1}$ at $2 \mathrm{~K}$. Meanwhile, the $\chi_{\mathrm{M}}$ value increases continuously along with the decrease in temperature. These results clearly manifest that the presence of antiferromagnetic coupling between octahedral $\mathrm{Co}$ (II) ions and the structure of the $\left[\mathrm{Co}_{3}\left(\mu_{2}-\mathrm{O}\right)_{2} \mathrm{~N}_{6}(\mathrm{COO})_{2}\right]$ trinuclear cluster may be responsible for this phenomenon. ${ }^{30-32}$ Meanwhile, the temperature dependence of the reciprocal susceptibilities $\left(\chi_{\mathbf{M}}{ }^{-1}\right)$ was plotted and it obeys well the $\mathrm{Cu}$ rie-Weiss law above $15 \mathrm{~K}$, with $C=11.11 \mathrm{~cm}^{3} \mathrm{~K} \mathrm{~mol}^{-1}$ and $\theta=-32.28 \mathrm{~K}$. The negative $\theta$ values reveals the dominant antiferromagnetic interactions between the $\mathrm{Co}(\mathrm{II})$ ions or 

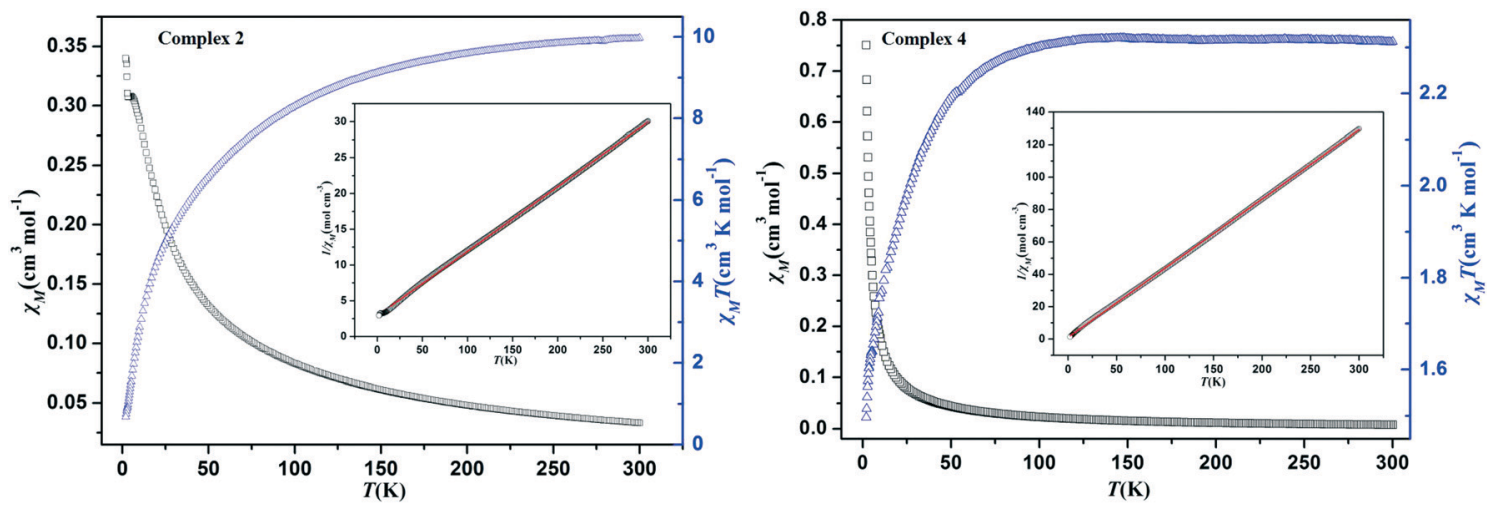

Fig. 6 Temperature dependence of $\chi_{M} T$ and $\chi_{M}$ for complexes 2 (left) and 4 (right) from 2 to $300 \mathrm{~K}$ under 1000 Oe field. Inset: Temperature dependence of $\chi_{M}{ }^{-1}$. The red solid lines represent the fitting results of the Curie-Weiss law $\chi_{M}=C /(T-\theta)$.

the presence of spin-orbit coupling. ${ }^{33}$ For complex 4, the $\chi_{\mathrm{M}} T$ value is 2.31 at $300 \mathrm{~K}$, which is larger than that for magnetically isolated spin-only $\mathrm{Co}(\mathrm{II})$ ions $\left(1.88 \mathrm{~cm}^{3}\right.$ $\mathrm{K} \mathrm{mol}^{-1}, S=3 / 2, g=2.0$ ). As the sample was cooling down, the $\chi_{\mathrm{M}} T$ value falls slowly until about $65 \mathrm{~K}$ and decreases sharply to $1.49 \mathrm{~cm}^{3} \mathrm{~K} \mathrm{~mol}^{-1}$ at $2 \mathrm{~K}$ (Fig. 6). This result reveals the presence of antiferromagnetic interaction between neighboring $\mathrm{Co}(\mathrm{II})$ ions. Meanwhile, the magnetic susceptibilities $\left(\chi_{M}{ }^{-1}\right)$ also perfectly obey the Curie-Weiss law in the temperature range of $2-300 \mathrm{~K}$, with $C=2.34 \mathrm{~cm}^{3} \mathrm{~K} \mathrm{~mol}^{-1}$ and $\theta=-2.63 \mathrm{~K}$. Both the negative $\theta$ and the decrease of $\chi_{\mathrm{M}} T$ can be attributed to the antiferromagnetic coupling interactions between the neighboring $\mathrm{Co}(\mathrm{II})$ ions. $^{34}$

\section{Dyes adsorption and mechanism}

Based on the different channels and pores of the titled MOFs, the investigation of guest capture in solution to explore the porosity and its potential application seems to be promising. In our work, three organic dyes (Fig. S7, $\uparrow$ acriflavine hydrochloride (AH), methyl orange (MO) and Congo red (GR)) with different functional groups $\left(-\mathrm{CH}_{3}\right.$ or $\left.-\mathrm{NH}_{2}\right)$ and molecular sizes were selected to investigate their influence on dye adsorption. ${ }^{35,36} 5 \mathrm{mg}$ of MOFs were dispersed in a $5 \mathrm{~mL}$ aqueous solution of $\mathrm{AH}$, MO or GR at a concentration of $20 \mathrm{ppm}$. Upon adsorption, the solution was tested at certain time intervals using UV-vis absorption spectroscopy.

The adsorption behaviors of five MOFs toward three kinds of organic dye aqueous solutions are shown in Fig. 7 and 8 and S8. $\uparrow$ As shown in Fig. 7, AH could be totally absorbed by the titled MOFs (1-5) after different adsorption times, and the removal percentage (\%) of $\mathrm{AH}$ can be calculated using the following equation: $[\mathrm{AH}$ removal $]=\left(c_{0}-c_{1}\right) / c_{0}$, where $c_{0}$ and $c_{1}$ represent the initial and final concentrations of the dye solution, respectively. After calculation, the AH adsorption rates are $92.80 \%$ for MOF-1 (after $540 \mathrm{~min}$ ), $91.33 \%$ for MOF-2 (after $540 \mathrm{~min}$ ), 92.17\% for MOF-3 (after $240 \mathrm{~min}$ ), 90.02\% for MOF-4 (after $360 \mathrm{~min}$ ) and $90.64 \%$ for MOF-5 (after $480 \mathrm{~min}$ ), respectively. The UV-vis curves of Fig. 8 exhibit that GR could also be absorbed by MOFs 1-5. MOF-3 (91.80\% after $480 \mathrm{~min}$ ) shows a better adsorption capacity for GR than the other four MOFs $(91.86 \%$ for $1,91.04 \%$ for $2,78.75 \%$ for 4 and $70.81 \%$ for 5 after $600 \mathrm{~min}$ ). As shown in Fig. S8, $\dagger$ MOF-2 exhibits an excellent capacity to absorb MO, while MOF-1, MOF-3, MOF-4 and MOF-5 exhibit no obvious adsorption for MO. Meanwhile, the crystal color changes of MOFs 1-5 after dye adsorption also indicate the adsorption process. Moreover, the adsorption capacity comparison of compounds 1-5 with other reported MOFs is shown in Table $\mathrm{S} 2 .+16 c, 19 a, 20,29,37-40$

As is well known, the porous MOFs can absorb organic dyes, which could be attributed to the chemical interactions ${ }^{41}$ or physical forces ${ }^{42}$ between organic dyes and MOFs. Thus, for the amino organic dyes (AH and GR), the possible adsorption mechanism could be explained using the strong interactions between amino organic dyes and MOFs. Because the $-\mathrm{NH}_{2}$ groups are both donors and acceptors of $\mathrm{H}$-bonds, they can facilitate interactions with the specific MOFs (Fig. S9†). As shown in Fig. $\mathrm{S} 10, \uparrow$ the $\mathrm{C}=\mathrm{O}$ vibration peaks of carboxylate groups from the titled MOFs can be observed at 1602 $\mathrm{cm}^{-1}$ (MOF-1), $1590 \mathrm{~cm}^{-1}$ (MOF-2), $1683 \mathrm{~cm}^{-1}$ (MOF-3), 1681 $\mathrm{cm}^{-1}$ (MOF-4) and $1685 \mathrm{~cm}^{-1}$ (MOF-5), respectively. These $\mathrm{C}=\mathrm{O}$ vibration peaks shift to $1593 \mathrm{~cm}^{-1}$ (MOF-1), $1583 \mathrm{~cm}^{-1}$ (MOF-2), $1674 \mathrm{~cm}^{-1}$ (MOF-3), $1674 \mathrm{~cm}^{-1}$ (MOF-4), and 1676 $\mathrm{cm}^{-1}$ (MOF-5) after AH adsorption, and shift to $1595 \mathrm{~cm}^{-1}$ (MOF-1), $1581 \mathrm{~cm}^{-1}$ (MOF-2), $1679 \mathrm{~cm}^{-1}$ (MOF-3), $1673 \mathrm{~cm}^{-1}$ (MOF-4) and $1679 \mathrm{~cm}^{-1}$ (MOF-5) after GR adsorption. Meanwhile, the $\mathrm{N}-\mathrm{H}$ vibration peaks of $\mathrm{NH}_{2}$ from $\mathrm{AH}$ and $\mathrm{GR}$ can be observed at $3302 \mathrm{~cm}^{-1}$ and $3464 \mathrm{~cm}^{-1}$, which further shift to $3286 \mathrm{~cm}^{-1}$ (MOF-1), $3285 \mathrm{~cm}^{-1}$ (MOF-2), $3290 \mathrm{~cm}^{-1}$ (MOF3), $3294 \mathrm{~cm}^{-1}$ (MOF-4), and $3293 \mathrm{~cm}^{-1}$ (MOF-5) after AH adsorption, and shift to $3386 \mathrm{~cm}^{-1}$ (MOF-1), $3451 \mathrm{~cm}^{-1}$ (MOF-2), $3451 \mathrm{~cm}^{-1}$ (MOF-3), $3448 \mathrm{~cm}^{-1}$ (MOF-4) and $3450 \mathrm{~cm}^{-1}$ (MOF5) after GR adsorption. Based on what have been mentioned above, we believe that the $\mathrm{H}$-bonds between the $-\mathrm{NH}_{2}$ groups (from amino organic dyes) and the uncoordinated $\mathrm{O}$ atoms in carboxyl groups and uncoordinated $-\mathrm{COOH}$ groups play a key role in the adsorption of organic dyes. Furthermore, MOF-4 and MOF-5 show a better adsorption capacity for $\mathrm{AH}$ 

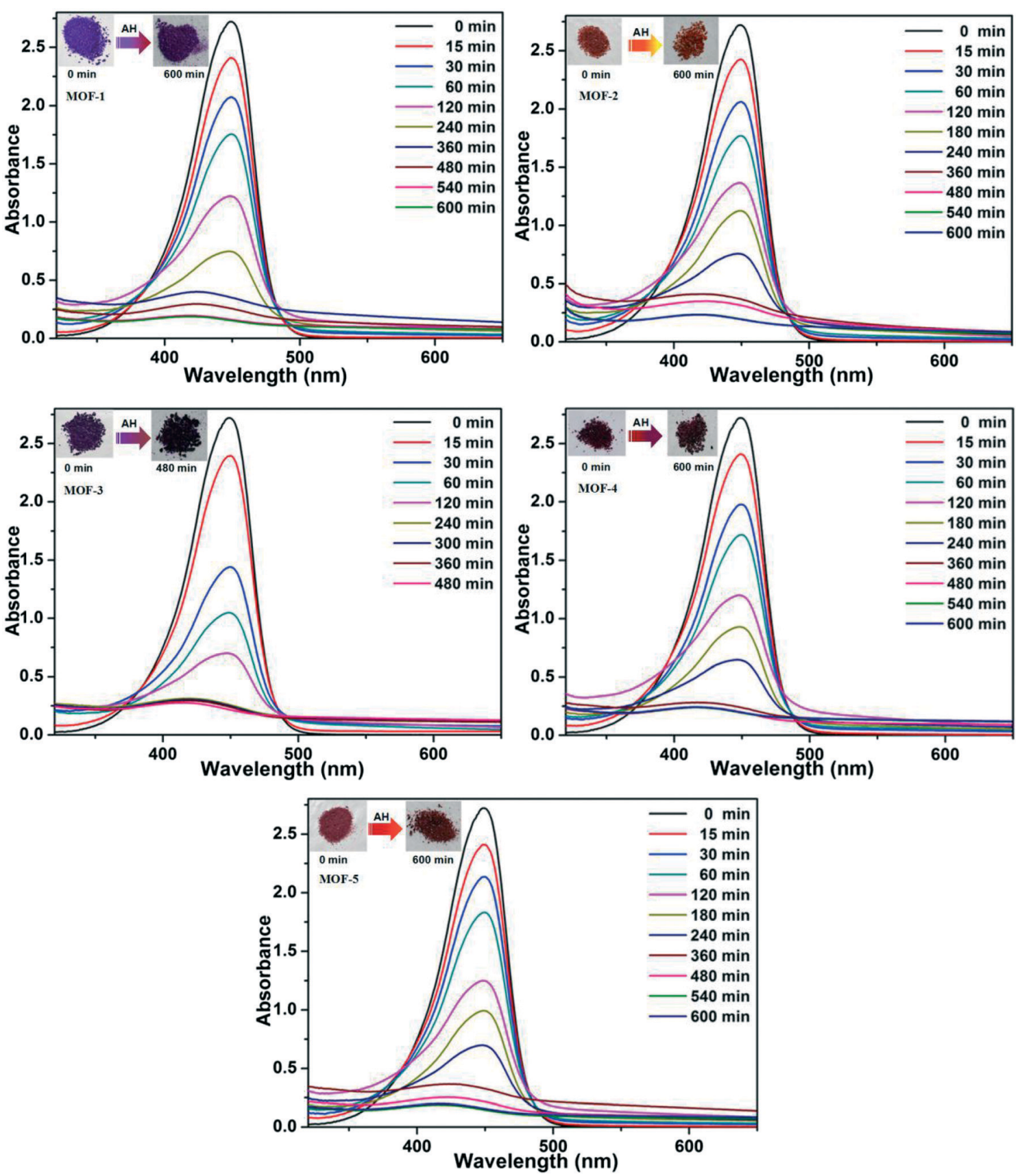

Fig. 7 UV-vis spectra for the uptake of AH from aqueous solutions at various time intervals for 1-5, respectively. The inset photographic images show the color change of MOFs before and after the adsorption of $\mathrm{AH}$.

than for GR, which may be caused by the different structures of organic dyes and MOFs (Fig. S11 $\dagger$ ).

As shown in Fig. S8, $\dagger$ MO and GR have similar structures except the $-\mathrm{NH}_{2}$ groups. However, GR can be adsorbed by all the titled MOFs, and MO can only be absorbed by MOF-2. Thus, we considered that the adsorption mechanism between MO and MOF-2 is different. Moreover, the IR spectrum of MOF-2 did not change before and after MO absorption (Fig. $\mathrm{S} 10 \dagger)$. Therefore, the possible reason for the MO absorption of MOF-2 may be caused by the physical forces between the MO and MOF-2.
Meanwhile, for practical applications, the reversibility of the adsorption--release process was investigated under the saturated solution of $\mathrm{NaCl}$ in DMF (Fig. S12 $\dagger$ ). ${ }^{37,43}$ Unfortunately, the results reveal that all complexes 1-5 cannot desorb GR, and the desorption capacities for GR and MO are also lower than $7.4 \%$ and $23.7 \%$, respectively. In order to investigate the stability of MOFs 1-5, the PXRD patterns of the recycled powders were obtained, as shown in Fig. S13. $\dagger$ The PXRD results revealed that the five Co(II) MOFs were stable in the dye adsorption process. 

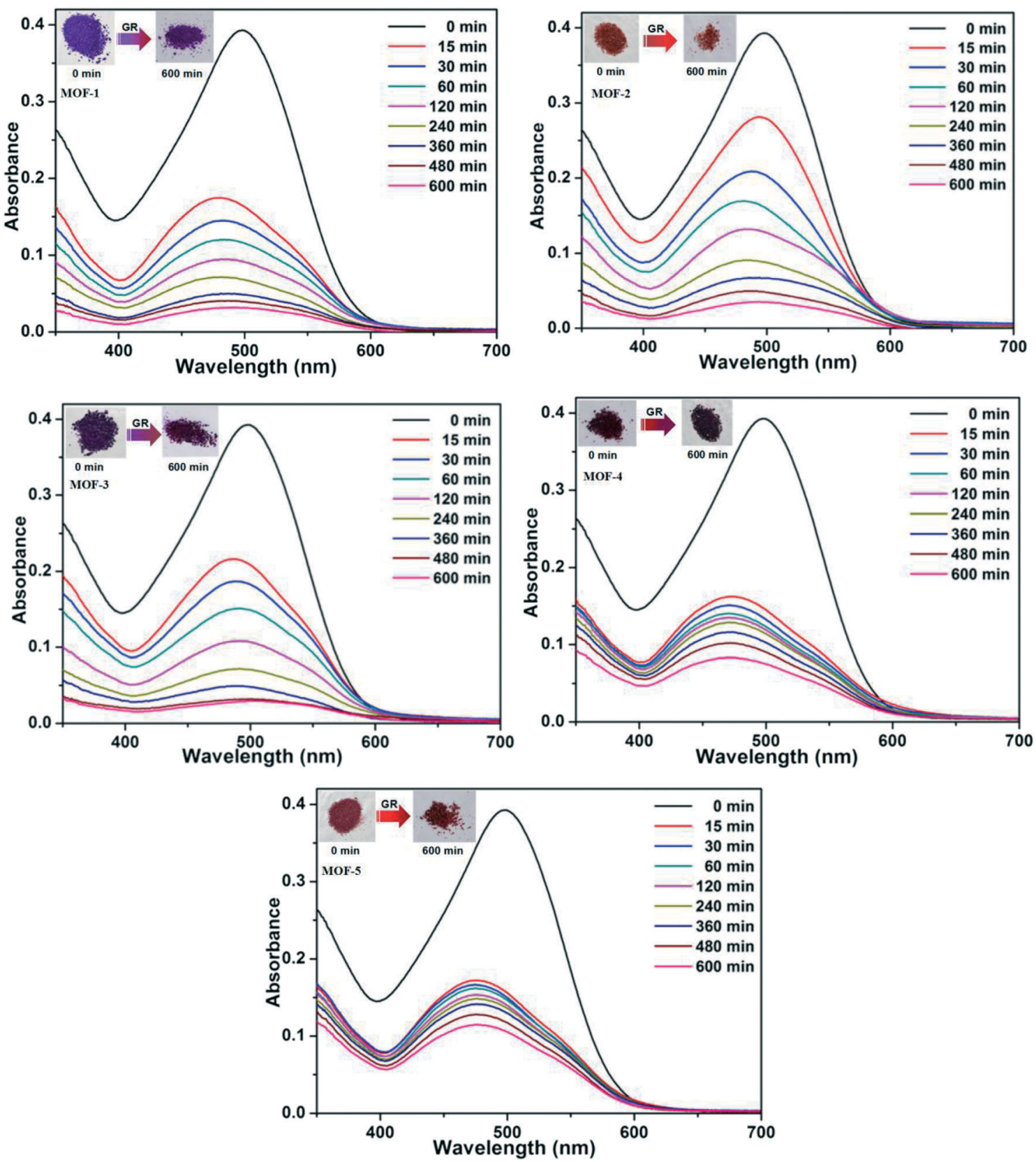

Fig. 8 UV-vis spectra for the uptake of GR from aqueous solutions at various time intervals for 1-5, respectively. The inset photographic images show the color change of MOFs before and after the adsorption of GR.

\section{Conclusions}

In summary, five MOFs were synthesized based on a semi-flexible 4-(3,5-dicarboxylatobenzyloxy)benzoic acid and five different imidazole bridging linkers (4,4'-bidpe, 4, $4^{\prime}$ bibp, 1,3-bitl, 3,5-bipd and tib) under solvothermal conditions, with the final packing structures exhibiting different architectures from a $2 \mathrm{D}$ polyrotaxane network to an unprecedented 3D framework. These results reveal that the configuration of the bridging $\mathrm{N}$-donor linkers has significant effects on the $\mathrm{H}_{3} \mathrm{~L}$ coordination modes, the pore size and the final structures. Variable-temperature mag- netic studies indicate that complexes 2 and 4 exhibit antiferromagnetic couplings between neighboring $\mathrm{Co}$ (II) ions. The dye adsorption and mechanism studies indicate that the pore size, the uncoordinated $O$ atoms in carboxyl groups and the uncoordinated carboxyl groups of the MOFs have significant effects on the dye adsorption capacity.

\section{Conflicts of interest}

There are no conflicts to declare. 


\section{Acknowledgements}

This research was supported by award given by the National Natural Science Foundation of China to C. F. Bi (No. 21371161) and the Specialized Research Fund for the Doctoral Program of Higher Education of China (No. 20120132110015). Open Access funding provided by the Max Planck Society.

\section{References}

1 (a) Z. Z. Lu, R. Zhang, Y. Z. Li, Z. J. Guo and H. G. Zheng, Chem. Commun., 2011, 47, 2919; (b) H. Wang, J. Xu, D. S. Zhang, Q. Chen, R. M. Wen, Z. Chang and X. H. Bu, Angew. Chem., Int. Ed., 2015, 54, 5966; (c) X. Zhao, X. H. Bu, T. Wu, S. T. Zheng, L. Wang and P. Y. Feng, Nat. Commun., 2013, 4, 2344; (d) X. M. Meng, C. B. Fan, C. F. Bi, Z. A. Zong, X. Zhang and Y. H. Fan, CrystEngComm, 2016, 18, 2901.

2 (a) D. S. Li, J. Zhao, Y. P. Wu, B. Liu, L. Bai, K. Zou and M. Du, Inorg. Chem., 2013, 52, 8091; (b) J. Z. Gu, X. X. Liang, Y. H. Cui, J. Wu, Z. F. Shi and A. M. Kirillov, CrystEngComm, 2017, 19, 2570; (c) D. S. Li, F. Fu, J. Zhao, Y. P. Wu, M. Du, K. Zou, W. W. Dong and Y. Y. Wang, Dalton Trans., 2010, 39, 11522.

3 (a) H. Furukawa, K. E. Cordova, M. O'Keeffe and O. M. Yaghi, Science, 2013, 341, 974; (b) D. S. Li, Y. P. Wu, J. Zhao, J. Zhang and J. Y. Lu, Coord. Chem. Rev., 2014, 261, 1; (c) X. L. Wang, X. T. Sha, G. C. Liu, N. L. Chen and Y. Tian, CrystEngComm, 2015, 17, 7290.

4 (a) Y. J. Cui, Y. F. Yue, G. D. Qian and B. L. Chen, Chem. Rev., 2012, 2, 703; (b) H. Yang, F. Wang, Y. X. Tan, T. H. Li and J. Zhang, Chem. - Asian J., 2012, 7, 1069; (c) M. J. Sie, Y. J. Chang, P. W. Cheng, P. T. Kuo, C. W. Yeh, C. F. Cheng, J. D. Chen and J. C. Wang, CrystEngComm, 2012, 14, 5505; (d) X. M. Meng, X. Zhang, P. F. Qi, Z. A. Zong, F. Jin and Y. H. Fan, RSC Adv., 2017, 7, 4855.

5 (a) J. C. Jin, L. Y. Pang, G. P. Yang, L. Hou and Y. Y. Wang, Dalton Trans., 2015, 44, 17222; (b) G. M. Sun, Y. M. Song, Y. Liu, X. Z. Tian, H. X. Huang, Y. Zhu, Z. J. Yuan, X. F. Feng, M. B. Luo, S. J. Liu, W. Y. Xu and F. Luo, CrystEngComm, 2012, 14, 5714; (c) Y. W. Li, H. Ma, Y. Q. Chen, K. H. He, Z. X. Li and X. H. Bu, Cryst. Growth Des., 2012, 12, 189; (d) Z. Y. Du, H. B. Xu and J. G. Mao, Inorg. Chem., 2006, 45, 9780.

6 (a) X. Wang, T. Qin, S. S. Bao, Y. C. Zhang, X. Shen, L. M. Zheng and D. R. Zhu, J. Mater. Chem. A, 2016, 4, 16484; (b) R. Lv, J. Y. Wang, Y. P. Zhang, H. Li, L. Y. Yang, S. Y. Liao, W. Gu and X. Liu, J. Mater. Chem. A, 2016, 4, 15494.

7 (a) H. Ogawa, K. Mori, K. Murashima, S. Karasawa and N. Koga, Inorg. Chem., 2016, 55, 717; (b) X. Y. Dong, C. D. Si, Y. Fan, D. C. Hu, X. Q. Yao, Y. X. Yang and J. C. Liu, Cryst. Growth Des., 2016, 16, 2062; (c) L. L. Johnston, J. H. Nettleman, M. A. Braverman, L. K. Sposato, R. M. Supkowski and R. L. LaDuca, Polyhedron, 2010, 29, 303; (d) Z. R. Pan, H. G. Zheng, T. W. Wang, Y. Song, Y. Z. Li, Z. J. Guo and S. R. Batten, Inorg. Chem., 2008, 47, 9528.

8 (a) E. Coronado and G. M. Espallargas, Chem. Soc. Rev., 2013, 42, 1525; (b) H. L. Sun, Z. M. Wang and S. Gao, Coord.
Chem. Rev., 2010, 254, 1081; (c) J. S. Miller and D. Gatteschi, Chem. Soc. Rev., 2011, 40, 3065.

9 (a) Y. B. He, W. Zhou, G. D. Qian and B. L. Chen, Chem. Soc. Rev., 2014, 43, 5657; (b) M. O'Keeffe and O. M. Yaghi, Chem. Rev., 2012, 112, 675; (c) B. L. Chen, N. W. Ockwig, A. R. Millward, D. S. Contreras and O. M. Yaghi, Angew. Chem., Int. Ed., 2005, 44, 4745; (d) Y. Yan, M. Juríček, F. X. Coudert, N. A. Vermeulen, S. Grunder, A. Dailly, W. Lewis, A. J. Blake, J. F. Stoddart and M. Schröder, J. Am. Chem. Soc., 2016, 138, 3371; (e) Y. Cui, Y. Yue, G. Qian and B. L. Chen, Chem. Rev., 2012, 112, 1126; $(f)$ G. Férey and C. Serre, Chem. Soc. Rev., 2009, 38, 1380.

10 (a) J. R. Li, J. Sculley and H. C. Zhou, Chem. Rev., 2011, 112, 869; (b) Z. Chen, R. Wang and J. Li, Chem. Mater., 2000, 12, 762; (c) S. R. Venna and M. A. Carreon, J. Am. Chem. Soc., 2009, 132, 76.

11 (a) H. Erer, O. Z. Yesilel and M. Arıcı, Cryst. Growth Des., 2015, 15, 3201; (b) J. An, S. J. Geib and N. L. J. Rosi, J. Am. Chem. Soc., 2009, 131, 8376; (c) J. Baldoví, E. Coronado, A. Gaita-Ariño, C. Gamer, M. GiménezMarqués and G. M. Espallargas, Chem. - Asian J., 2014, 20, 10695; (d) F. Nouar, J. Eckert, J. F. Eubank, P. Forster and M. Eddaoudi, J. Am. Chem. Soc., 2009, 131, 2864.

12 (a) D. J. Wales, J. Grand, V. P. Ting, R. D. Burke, K. J. Edler, C. R. Bowen, S. Mintova and A. D. Burrows, Chem. Soc. Rev., 2015, 44, 4290; (b) P. Canepa, K. Tan, Y. J. Du, H. B. Lu, Y. J. Chabal and T. Thonhauser, J. Mater. Chem. A, 2015, 3, 986.

13 A. H. Chughtai, N. H. Ahmad, A. Younus, A. Laypkov and F. Verpoort, Chem. Soc. Rev., 2015, 44, 6804.

14 M. Yoon, R. Srirambalaji and K. Kim, Chem. Rev., 2011, 112, 1196.

15 (a) S. Han, Y. H. Wei, C. Valente, I. Lagzi, J. J. Gassensmith, A. Coskun, J. F. Stoddart and B. A. Grzybowski, J. Am. Chem. Soc., 2010, 132, 16358; (b) X. J. Dui, W. B. Yang, X. Y. Wu, X. Kuang, J. Z. Liao, R. Yu and C. Z. Lu, Dalton Trans., 2015, 44, 9496; (c) Y. C. He, J. Yang, W. Q. Kan and J. F. Ma, CrystEngComm, 2013, 15, 848.

16 (a) M. J. Dong, M. Zhao, S. Ou, C. Zou and C. D. Wu, Angew. Chem., Int. Ed., 2014, 53, 1575; (b) H. N. Wang, F. H. Liu, X. L. Wang, K. Z. Shao and Z. M. Su, J. Mater. Chem. A, 2013, 1, 13060; (c) F. L. Hu, Y. X. Shi, H. H. Chen and J. P. Lang, Dalton Trans., 2015, 44, 18795.

17 J. W. Hou, P. D. Sutrisna, Y. T. Zhang and V. Chen, Angew. Chem., Int. Ed., 2016, 55, 3947.

18 (a) B. Adhikari, G. Palui and A. Banerjee, Soft Mater., 2009, 5, 3452; (b) M. L. Zhang, Q. F. Yao, C. Lu, Z. H. Li and W. X. Wang, ACS Appl. Mater. Interfaces, 2014, 6, 20225; (c) S. R. Zhang, J. Li, D. Y. Du, J. S. Qin, S. L. Li, W. W. He, Z. M. Su and Y. Q. Lan, J. Mater. Chem. A, 2015, 3, 23426.

19 (a) Y. Han, S. Sheng, F. Yang, Y. B. Xie, M. J. Zhao and J. R. Li, J. Mater. Chem. A, 2015, 3, 12804; (b) S. Chen, J. Zhang, C. Zhang, Q. Yue, Y. Li and C. Li, Desalination, 2010, 252, 149.

20 E. Haque, V. Lo, A. I. Minett, A. T. Harris and T. L. Church, J. Mater. Chem. A, 2014, 2, 193.

21 (a) V. A. Blatov, IUCr CompComm Newsletter, 2006, vol. 7, p. 4; (b) V. A. Blatov, A. P. Shevchenko and V. N. Serezhkin, 
J.Appl. Crystallogr., 2000, 33, 1193; (c) V. A. Blatov, M. O'Keeffe and D. M. Proserpio, CrystEngComm, 2010, 12, 44, see also, http://www.topos.ssu.Samara.ru.

22 O. D. Friedrichs, Program SYSTRE 1.14 beta, http://gavrog. sourceforge.net/, 2007.

23 V. A. Blatov, A. P. Shevchenko and D. M. Proserpio, Cryst. Growth Des., 2014, 14, 3576.

24 G. M. Sheldrick, SHELXTL NT, version 5.1, Program for Solution and Refinement of Crystal Structures, University of GÖttingen, GÖttingen, Germany, 1997.

25 Bruker 2000, SMART, version 5.0, SAINT-plus version 6, SHELXTL, version 6.1, and SADABS version 2.03, Bruker AXS Inc., Madison, WI.

26 (a) A. L. Spek, J. Appl. Crystallogr., 2003, 36, 7; (b) A. L. Spek, PLATON, A Multipurpose Crystallographic Tool, Utrecht University, Utrecht, The Netherlands, 2002.

27 (a) F. Guo, B. Zhu, M. Liu, X. Zhang, J. Zhang and J. Zhao, CrystEngComm, 2013, 15, 6191; (b) L. Fan, X. Zhang, W. Zhang, Y. Ding, W. Fan, L. Sun, Y. Pang and X. Zhao, Dalton Trans., 2014, 43, 6701; (c) X. Zhang, L. Fan, W. Zhang, W. Fan, L. Sun and X. Zhao, CrystEngComm, 2014, 16, 3203; (d) B. Liu, L. Wei, N. N. Li, W. P. Wu, H. Miao, Y. Y. Wang and Q. Z. Shi, Cryst. Growth Des., 2014, 14, 1110.

28 S. B. Zhou, X. F. Wang, C. C. Du, D. Z. Wang and D. Z. Jia, CrystEngComm, 2017, 19, 3124.

29 W. Yan, L. J. Han, H. L. Jia, K. Shen, T. Wang and H. G. Zheng, Inorg. Chem., 2016, 55, 8816.

30 O. Kahn, Molecular Magnetism, VCH Publishers, New York, 1993.
31 D. S. Li, J. Zhao, Y. P. Wu, B. Liu, L. Bai, K. Zou and M. Du, Inorg. Chem., 2013, 52, 8091.

32 M. L. Han, Y. P. Duan, D. S. Li, H. B. Wang, J. Zhao and Y. Y. Wang, Dalton Trans., 2014, 43, 15450.

33 X. J. Li, X. Y. Wang, S. Gao and R. Cao, Inorg. Chem., 2006, 45, 1508.

34 X. Y. Dong, C. D. Si, Y. Fan, D. C. Hu, X. Q. Yao, Y. X. Yang and J. C. Liu, Cryst. Growth Des., 2016, 16, 2062.

35 (a) M. J. Dong, M. Zhao, S. Ou, C. Zou and C. D. Wu, Angew. Chem., Int. Ed., 2014, 53, 1575; (b) H. N. Wang, F. H. Liu, X. L. Wang, K. Z. Shao and Z. M. Su, J. Mater. Chem. A, 2013, 1, 13060.

36 Z. F. Zhu, Y. L. Bai, L. L. Zhang, D. F. Sun, J. H. Fang and S. R. Zhu, Chem. Commun., 2014, 50, 14674.

37 Z. Zhu, X. M. Meng, D. M. Zhang, X. Zhang, M. Wang, F. Jin and Y. H. Fan, J. Solid State Chem., 2017, 248, 109.

38 S. N. Sheng, Y. Han, B. Wang, C. Zhao, F. Yang, Y. B. Xie and J. R. Li, J. Solid State Chem., 2016, 233, 143.

39 L. Xiao, Y. Xiong, S. Tian, C. He, Q. Su and Z. Wen, Chem. Eng. J., 2015, 265, 157.

40 S. L. Xiao, Y. H. Li, P. J. Ma and G. H. Cui, Inorg. Chem. Commun., 2013, 37, 54.

41 H. Hahm, S. Kim, H. Ha, S. Jung, Y. Kim, M. Yoon and M. Kim, CrystEngComm, 2015, 17, 8418.

42 M. Arshadi, A. R. Faraji, A. Moaddeli, A. Khalafi-Nezhad and H. Firouzabadi, Chem. Eng. Res. Des., 2016, 109, 707.

43 W. H. Huang, J. Z. Li, L. S. Gao, Y. X. Wang, S. Y. Liu, M. Jiang, T. Liu and Y. Y. Wang, Dalton Trans., 2016, 45, 15060. 